\title{
Study on the Corroded Hollow Section RC Columns Strengthened by ICCP-SS System
}

\author{
Ju Chen ${ }^{1}$, Jun Wang ${ }^{2, *}$, Ji-Hua Zhu ${ }^{2, *}$, Yuan Feng ${ }^{2}$ and Cheng-Bin Liu ${ }^{1}$ \\ 1 Department of Civil Engineering, Zhejiang University, Hangzhou 310058, China; cecj@zju.edu.cn (J.C.); \\ lcb@zju.edu.cn (C.-B.L.) \\ 2 Guangdong Province Key Laboratory of Durability for Marine Civil Engineering, School of Civil Engineering, \\ Shenzhen University, Shenzhen 518060, China; fengyuan2017@email.szu.edu.cn \\ * Correspondence: wangjun123@szu.edu.cn (J.W.); zhujh@szu.edu.cn (J.-H.Z.)
}

Citation: Chen, J.; Wang, J.; Zhu,

J.-H.; Feng, Y.; Liu, C.-B. Study on the Corroded Hollow Section RC Columns Strengthened by ICCP-SS System. Buildings 2021, 11, 197. https://doi.org/10.3390/buildings 11050197

Academic Editor: Giovanni Minafò

Received: 27 March 2021

Accepted: 6 May 2021

Published: 8 May 2021

Publisher's Note: MDPI stays neutral with regard to jurisdictional claims in published maps and institutional affiliations.

Copyright: (c) 2021 by the authors. Licensee MDPI, Basel, Switzerland. This article is an open access article distributed under the terms and conditions of the Creative Commons Attribution (CC BY) license (https:// creativecommons.org/licenses/by/ $4.0 /)$.

\begin{abstract}
In this paper, the behavior of corroded hollow section RC (reinforced concrete) columns strengthened by an Impressed Current Cathodic Protection and Structural Strengthening (ICCP-SS) system was investigated. The Carbon Fabric-Reinforced Cementitious Matrix (C-FRCM) composite serves dual functions in the intervention method. The axial compression behavior of strengthened columns was firstly investigated through axial compression tests. The influence of corrosion ratio and C-FRCM strengthening on the test results, such as failure mode, load-displacement curve, ultimate load, and ultimate strain, were analyzed. Test results showed that the ultimate load of the corroded specimens could be enhanced significantly by C-FRCM, and the ductility of the strengthened specimens was larger than the specimens without strengthening, especially for the specimens with higher corrosion ratios. Secondly, the effects of the ICCP-SS system on the migration and distribution laws of chloride ions $\left(\mathrm{Cl}^{-}\right)$in hollow section $\mathrm{RC}$ columns were analyzed by the potentiometric titration method. The main parameters include charging time, current density, and salt addition. Results showed that the rebar would have a certain blocking effect on the migration of $\mathrm{Cl}^{-}$, which resulted in that the content of $\mathrm{Cl}^{-}$in the inner side of the rebar was always larger than that of the outer side; and research results also showed that the increase of impressed current density and charge time would reduce the $\mathrm{Cl}^{-}$content on both sides of the rebar, while the impressed current would cause the $\mathrm{Cl}^{-}$near the rebars to constantly move toward the vicinity of CFRP.
\end{abstract}

Keywords: axial compression behavior; corroded RC columns; FRCM; hollow section; ICCP-SS system

\section{Introduction}

The hollow section reinforced concrete (RC) columns have the advantages of better seismic performance, larger moment of inertia, lighter weight, and higher material efficiency compared with compact section RC columns. Both their structural and economic benefits have led them to be widely used in electric transmission poles, bridge piers, and other structures [1,2]. When hollow section RC columns are used in coastal areas, the corrosion of rebars caused by chloride ingression is inevitable, and a protective solution must be chosen [3]. For durability problems in RC structures, Impressed Current Cathodic Protection (ICCP) and Structural Strengthening (SS) are commonly used methods for protection. However, both methods have their own disadvantages: ICCP technology is unable to make up for the bearing capacity loss caused by corrosion; while for SS, the corrosion of rebars is left uncontrolled and can lead to additional problems in the future. To solve both of these issues, a dual-functional intervention method, namely the ICCP-SS method, which combines the two technologies, has been proposed in previous research [4-8].

However, to achieve the goal of combining ICCP and SS, a suitable material must first be found that can be used both as the ICCP anode and structural reinforcement $[4,5]$. Research results provided by Zhu et al. [8] showed that CFRP can be used as a dual functional material for RC structures, serving as not only a strengthening material but also 
as an ICCP anode. Furthermore, the research results of Wei et al. [9] indicated that the CFRP could be bonded using an inorganic cementing material, instead of an organic adhesive material such as epoxy resin. This not only fulfilled the electric conductivity requirements of the ICCP method but also ensured good mechanical properties, as discussed by Wei et al. [9]. The resulting composite material that combines inorganic cementitious materials (cement paste, mortar, or concrete) and fiber-reinforced plastics (FRP) is called a FabricReinforced Cementitious Matrix (FRCM) or Textile RC/Mortar (TRC/TRM) [9]. This FRCM can be utilized both as an auxiliary anode in ICCP and as a strengthening material in the SS technique to form the ICCP-SS system [4-9]. In engineering practice, the FRCM are bonded with the external surfaces of columns or the tensile regions of beams, and the CFRP in FRCM are connected with the positive pole while the rebars are connected with the negative pole of the external power supply; by doing this, the ICCP-SS system can be constructed in actual engineering [10]. Nowadays, the ICCP-SS system has been applied in the existing structures; for example, the ICCP-SS system was installed on one of the docks of China Merchants Port and the Guangzhou-Shenzhen highway in Guangdong province, China [10].

In recent years, some scholars [11-16] have studied and confirmed the effectiveness of FRCM in strengthening RC columns without the use of ICCP. Zhu and Su [4,5] studied the protective effect of an ICCP-SS system on solid section RC beams and RC columns under the corrosion of chlorine salt. Research results showed that the ICCP-SS system can not only delay the further corrosion of rebars but also improve the bearing capacity of the corroded members.

However, research on the axial compression properties of corroded hollow section RC columns, as mentioned above, strengthened by the ICCP-SS method has yet to be reported. Furthermore, unlike solid sections, hollow section RC columns have the additional risk of chloride ingression from the inner side of the concrete column wall. Therefore, the distribution of $\mathrm{Cl}^{-}$near the rebars under ICCP cathodic protection for hollow section RC columns must be investigated to determine the effectiveness of the protective system and its effect on structural performance. It should be noted that the technique of ICCP in this manuscript served as the cathodic protection (CP) rather than the electrochemical chloride extraction (ECE), because the current densities used in this paper were relatively small and the protection time of ICCP used in engineering practice was throughout the service life [17]. Hence, the primary purpose of the ICCP technique was to retain the potential of rebar in concrete more negative so as to prevent further corrosion, and the influence of electric field formed between the anode and cathode on the migration and distribution mechanism of $\mathrm{Cl}^{-}$were also investigated in this paper.

\section{Experimental Section}

For the FRCM confined corroded RC hollow columns, a total of 12 columns subjected to axial compression were tested in the structural laboratory of Shenzhen University. The tested columns had a hollow ratio $\rho(\rho=d / D$, where $d$ and $D$ are the inner and outer diameters of the hollow columns, respectively) of 0.53 and a height $L$ of $1000 \mathrm{~mm}$. The main purpose was to investigate the degree of protection that FRCM could provide for the corroded RC hollow columns when subject to varying corrosion ratios.

To investigate the migration and distribution laws of $\mathrm{Cl}^{-}$in the $\mathrm{RC}$ hollow columns under the protection of the ICCP-SS system, a further 12 RC hollow columns were tested. The tested columns had a hollow ratio $\rho$ of 0.53 and a height $L$ of $500 \mathrm{~mm}$.

It should be noted that the longitudinal rabars and stirrups were deformed rebars and round rebars, respectively. The longitudinal rabars and stirrups were tied together, and the mill scale was scraped before casting concrete. 


\subsection{The FRCM Confined Corroded RC Hollow Columns under Axial Compression}

\subsubsection{Axial Compression Test Specimens}

A total of 12 specimens were designed in the axial compression test, the height of all specimens was $1000 \mathrm{~mm}$, and the outer diameter (excluding FRCM) and inner diameter of all specimens were $300 \mathrm{~mm}$ and $160 \mathrm{~mm}$ (hollow ratio $\rho=0.53$ ). The 12 specimens were divided into two groups of 6 , namely group 1 and 2 . Test specimens in group 1 were strengthened using FRCM, while those in group 2 were not. Both groups of specimens were subjected to electrified accelerated corrosion with a current density of $0.5 \mathrm{~mA} / \mathrm{cm}^{2}$ for different time spans to achieve different corrosion ratios (the corrosion ratio was defined as the ratio of mass loss after corrosion to the mass before corrosion, and the corrosion ratios designed in this paper were $0 \%, 5 \%, 10 \%, 15 \%, 20 \%$, and $25 \%$ ). The electrifying time required to reach a certain corrosion ratio can be calculated according to reference [18]. Details of the test specimens are shown in Table 1.

Table 1. Details of axial compression specimens.

\begin{tabular}{|c|c|c|c|c|c|c|c|c|}
\hline Group & Specimen & FRCM & $\mathrm{D} / \mathrm{mm}$ & $d / \mathrm{mm}$ & $\rho$ & $I_{\mathrm{a}} / \mathrm{mA} / \mathrm{cm}^{2}$ & $T_{\mathrm{a}} /$ Hour & $\begin{array}{c}\text { Corrosion } \\
\text { Ratio }\end{array}$ \\
\hline \multirow{6}{*}{1} & I-0-S & Yes & 300 & 160 & 0.53 & 0.5 & 0 & $0 \%$ \\
\hline & I-5-S & Yes & 300 & 160 & 0.53 & 0.5 & 225.0 & $5 \%$ \\
\hline & I-10-S & Yes & 300 & 160 & 0.53 & 0.5 & 450.0 & $10 \%$ \\
\hline & I-15-S & Yes & 300 & 160 & 0.53 & 0.5 & 675.0 & $15 \%$ \\
\hline & I-20-S & Yes & 300 & 160 & 0.53 & 0.5 & 899.9 & $20 \%$ \\
\hline & I-25-S & Yes & 300 & 160 & 0.53 & 0.5 & 1124.9 & $25 \%$ \\
\hline \multirow{6}{*}{2} & $\mathrm{I}-0$ & No & 300 & 160 & 0.53 & 0.5 & 0 & $0 \%$ \\
\hline & $\mathrm{I}-5$ & No & 300 & 160 & 0.53 & 0.5 & 225.0 & $5 \%$ \\
\hline & $\mathrm{I}-10$ & No & 300 & 160 & 0.53 & 0.5 & 450.0 & $10 \%$ \\
\hline & $\mathrm{I}-15$ & No & 300 & 160 & 0.53 & 0.5 & 675.0 & $15 \%$ \\
\hline & $\mathrm{I}-20$ & No & 300 & 160 & 0.53 & 0.5 & 899.9 & $20 \%$ \\
\hline & $\mathrm{I}-25$ & No & 300 & 160 & 0.53 & 0.5 & 1124.9 & $25 \%$ \\
\hline
\end{tabular}

Note: In Table $1, \rho$ is the hollow ratio of the specimens, and $\rho=d / D ; I_{\mathrm{a}}$ is the current density used to accelerate corrosion, and $T_{\mathrm{a}}$ is the electrifying time for accelerated corrosion. In the name of a specimen, I means that the specimen is charged with direct current; the following number represents the corrosion ratio of the specimen, while $S$ indicates that the specimen is strengthened by FRCM. For example, the specimen named I-15-S means the specimen is subjected to direct current, the corrosion ratio of rebar is 15\%, and it is strengthened by FRCM.

The geometric size and arrangement of steel reinforcement in all 12 specimens in Table 1 are the same. The specimens are all equipped with 8 longitudinal rebars with diameter of $12 \mathrm{~mm}$ and 7 stirrups with diameter of $6 \mathrm{~mm}$. The details of the test specimens are shown in Figure 1. 


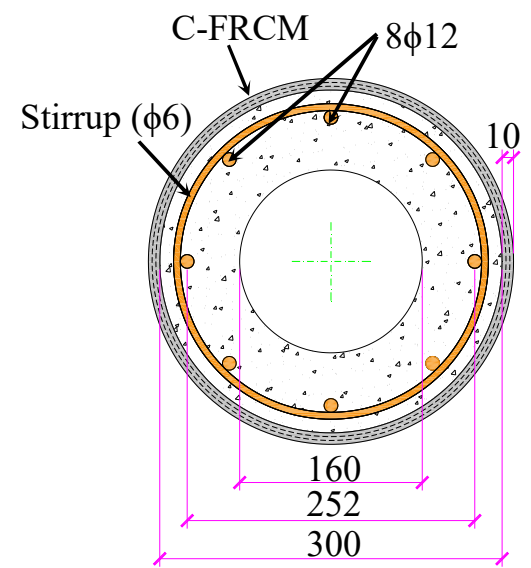

(a) Specimen cross-section

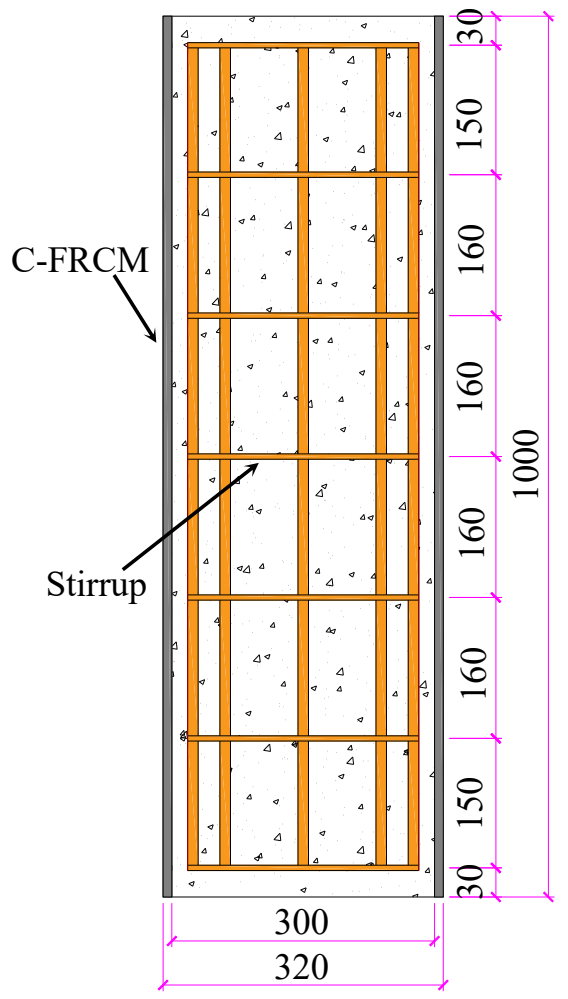

(b) Specimen front view

Figure 1. Details of the axial compression specimens (unit: $\mathrm{mm}$ ).

\subsubsection{Corrosion and Strengthening of Specimens}

In this paper, the process of corroding each specimen to a specified ratio was accelerated through the use of a DC stabilized power supply. Firstly, the specimen was wrapped with a stainless steel mesh, then submerged in a $3 \%$ (mass percent) solution of $\mathrm{NaCl}$, it should be noted that the solution of $\mathrm{NaCl}$ was replaced every three days to maintain a stable solution concentration. Finally, the 8 longitudinal rebars and the stainless steel mesh were connected to the positive and negative electrodes of the DC power supply, respectively. The configuration of the specimens subjected to accelerated corrosion is shown in Figure 2.

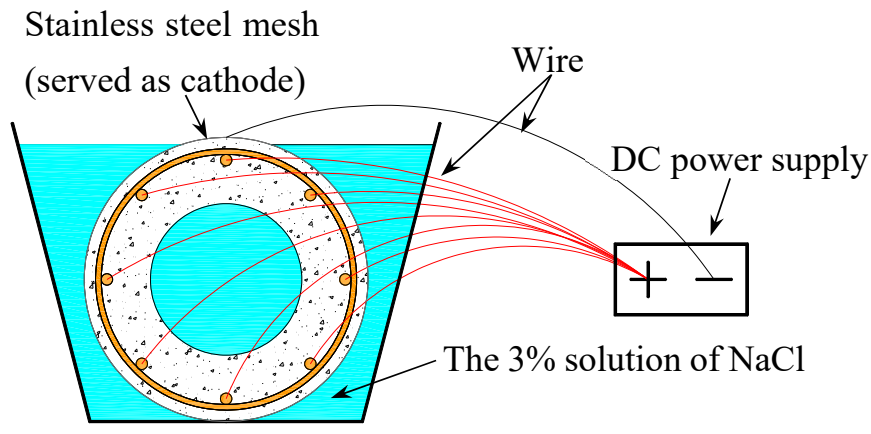

(a) Schematic diagram

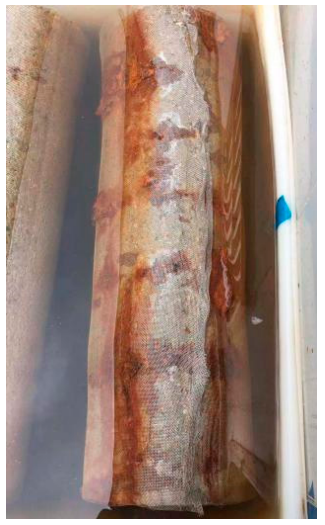

(b) Physical diagram

Figure 2. Configuration of specimens subjected to accelerated corrosion. 


\subsection{Test Specimens for Chloride Migration Investigation with ICCP-SS System}

\subsubsection{Details of Test Specimens}

For the investigation of $\mathrm{Cl}^{-}$migration, a total of 12 additional specimens were designed. The designed specimens were evenly divided into 2 groups, namely group 1 and 2. Salt was added into the concrete for specimens in group 1, and none was added for specimens in group 2. The height of all specimens was $500 \mathrm{~mm}$, the outer diameter (excluding FRCM) and inner diameter of all specimens were $300 \mathrm{~mm}$ and $160 \mathrm{~mm}$, respectively (hollow ratio $\rho=0.53$ ). Test specimens were protected by ICCP for 4,7 , and 10 months with current densities of $20 \mathrm{~mA} / \mathrm{m}^{2}$ and $60 \mathrm{~mA} / \mathrm{m}^{2}$, as shown in Table 2 .

Table 2. Details of specimens under the protection of ICCP-SS system.

\begin{tabular}{|c|c|c|c|c|c|c|c|c|}
\hline Group & Specimen & ICCP & Adding $\mathrm{Cl}^{-}$ & $\mathrm{D} / \mathrm{mm}$ & $d / \mathrm{mm}$ & $\rho$ & $I_{\mathrm{p}} / \mathrm{mA} / \mathrm{m}^{2}$ & $T_{\mathrm{p}} /$ Month \\
\hline \multirow{6}{*}{1} & IC-4-S-Cl & Yes & Yes & 300 & 160 & 0.53 & 20 & 4 \\
\hline & IC-7-S-Cl & Yes & Yes & 300 & 160 & 0.53 & 20 & 7 \\
\hline & IC-10-S-Cl & Yes & Yes & 300 & 160 & 0.53 & 20 & 10 \\
\hline & IC-4-L-Cl & Yes & Yes & 300 & 160 & 0.53 & 60 & 4 \\
\hline & IC-7-L-Cl & Yes & Yes & 300 & 160 & 0.53 & 60 & 7 \\
\hline & IC-10-L-Cl & Yes & Yes & 300 & 160 & 0.53 & 60 & 10 \\
\hline \multirow{6}{*}{2} & IC-4-S & Yes & No & 300 & 160 & 0.53 & 20 & 4 \\
\hline & IC-7-S & Yes & No & 300 & 160 & 0.53 & 20 & 7 \\
\hline & IC-10-S & Yes & No & 300 & 160 & 0.53 & 20 & 10 \\
\hline & IC-4-L & Yes & No & 300 & 160 & 0.53 & 60 & 4 \\
\hline & IC-7-L & Yes & No & 300 & 160 & 0.53 & 60 & 7 \\
\hline & IC-10-L & Yes & No & 300 & 160 & 0.53 & 60 & 10 \\
\hline
\end{tabular}

Note: In Table $2, I_{\mathrm{p}}$ is the current density used for ICCP protection. In the name of specimens, IC means that the ICCP protection was applied; 4, 7, and 10 indicate that the ICCP protection lasted for 4, 7, or 10 months; S and $L$ represent that the current density used for ICCP protection was small $\left(20 \mathrm{~mA} / \mathrm{m}^{2}\right)$ or large $\left(60 \mathrm{~mA} / \mathrm{m}^{2}\right)$, respectively; $\mathrm{Cl}$ means that $3 \%$ (mass percent) of $\mathrm{NaCl}$ was pre-added into the concrete. For example, the specimen named IC-7-L-Cl means that $3 \%$ of $\mathrm{NaCl}$ was pre-added into the concrete, and the specimen was protected by ICCP for 7 months with a current density of $60 \mathrm{~mA} / \mathrm{m}^{2}$.

The geometric size and arrangement of rebars of all the specimens in Table 2 are the same; that is, the specimens are all equipped with 8 longitudinal rebars with a diameter of $12 \mathrm{~mm}$ and 4 stirrups with a diameter of $6 \mathrm{~mm}$. The details of the test specimens are shown in Figure 3.

\subsubsection{ICCP-SS System}

For the structural strengthening aspect of the ICCP-SS method, specimens had one layer of CFRP located in the middle of the cementitious material surrounding the column. The total thickness of the FRCM was $10 \mathrm{~mm}$, and the overlapping length of the CFRP along the circumferential direction was $150 \mathrm{~mm}$.

Before ICCP-SS protection, a solution of $\mathrm{NaCl}$ ( $3 \%$ by mass) was added into the cavity of the specimens to simulate the corrosion phenomena of a marine environment, it should be noted that the solution of $\mathrm{NaCl}$ was replaced every three days to maintain a stable solution concentration. During the ICCP-SS protection, the CFRP was used as an anode and connected with the positive electrode of the power supply; the longitudinal rebars were used as a cathode and connected with the negative electrode of the power supply. The details of the setup of the ICCP-SS system for the specimens protected against a seawater environment are shown in Figure 4. 


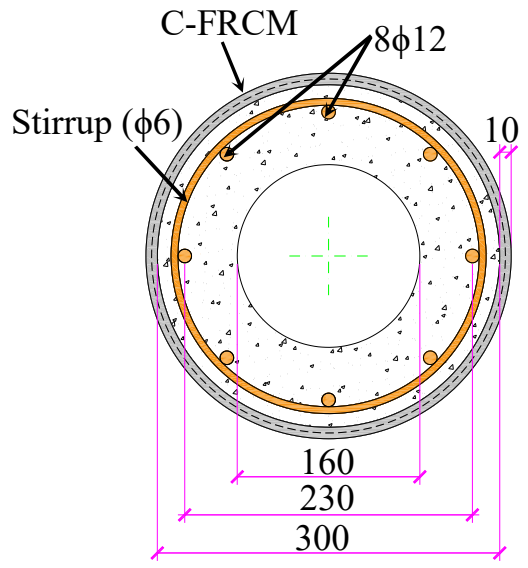

(a) Specimen cross-section

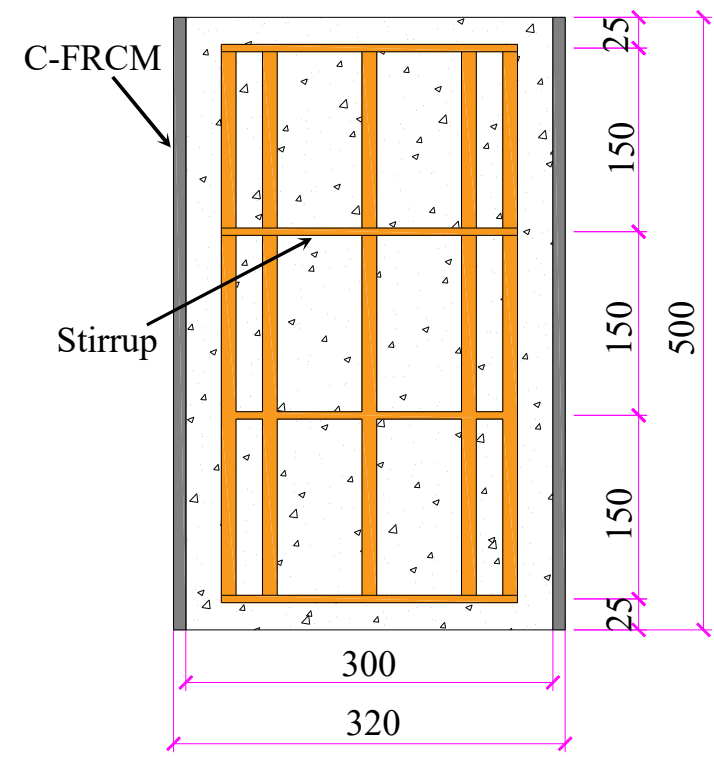

(b) Specimen front view

Figure 3. Details of specimens under the protection of ICCP-SS (unit: mm).

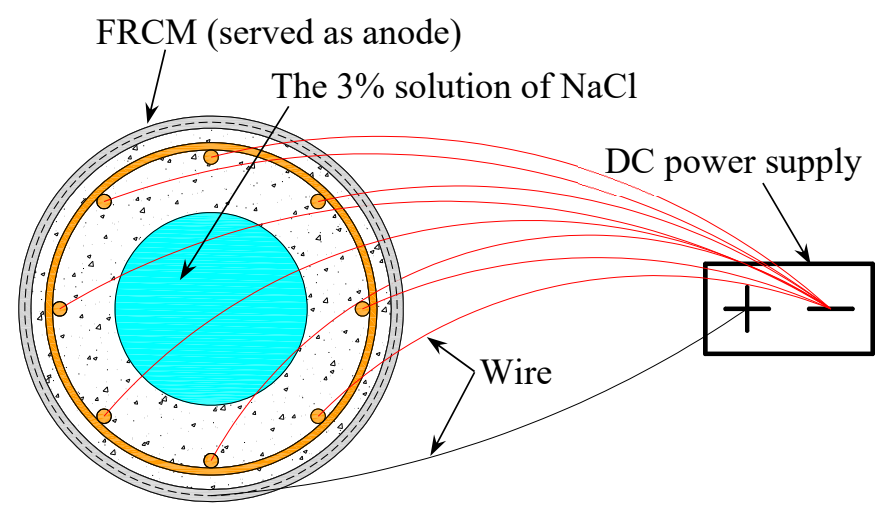

(a) Schematic diagram

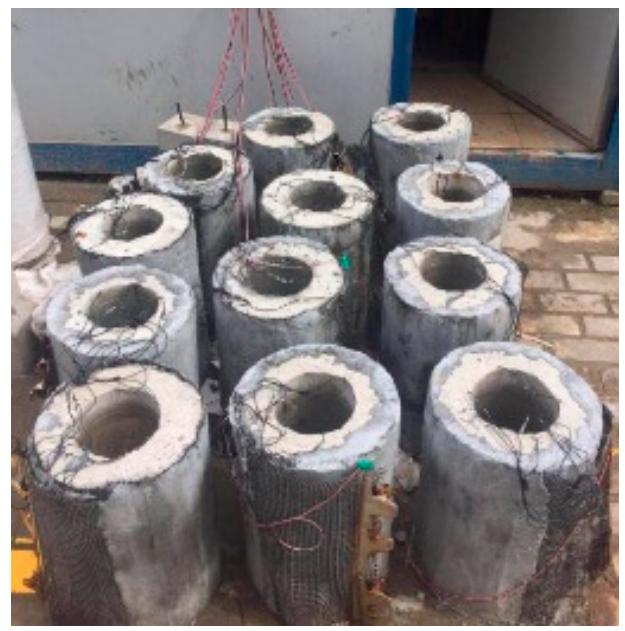

(b) Physical diagram

Figure 4. Schematic and physical diagrams of specimens protected by the ICCP-SS system.

\subsection{Material Properties}

2.3.1. Mechanical Properties of Concrete, Rebars, Cementitious Material, and CFRP

The rebars and concrete of all test specimens in Tables 1 and 2 belonged to the same batch of materials. The measured yield strength, ultimate strength, and elastic modulus of the longitudinal rebar with a diameter of $12 \mathrm{~mm}$ were $377.8 \mathrm{MPa}, 468.5 \mathrm{MPa}$, and $180.9 \mathrm{GPa}$, respectively.

The concrete was mixed according to the ingredients showed in Table 3. The compressive strength of $150 \mathrm{~mm}$ cube of the concrete was $33.5 \mathrm{MPa}$. 
Table 3. Mix design of concrete.

\begin{tabular}{ccccc}
\hline Composition & Cement $/ \mathbf{k g} / \mathbf{m}^{\mathbf{3}}$ & $\begin{array}{c}\text { Coarse } \\
\text { Aggregate } / \mathbf{k g} / \mathbf{m}^{\mathbf{3}}\end{array}$ & Sand $/ \mathbf{k g} / \mathbf{m}^{\mathbf{3}}$ & Water $/ \mathbf{k g} / \mathbf{m}^{\mathbf{3}}$ \\
\hline Amount & 386.1 & 1194.5 & 643.6 & 197.6 \\
\hline
\end{tabular}

The FRCM composite used as structural strengthening consisted of a cementitious material binder and one or more layers of CFRP. The cementitious material used included cement, silica sand, water, $3 \mathrm{~mm}$ shortcut carbon fiber filament, water-reducing agent, etc. The compressive strengths of the cementitious matrix were obtained by a cylinder compressive test in accordance with ASTM C39 [19], the average compressive strength and flexural strength of a prism specimen with the dimensions $40 \times 40 \times 160 \mathrm{~mm}$ were 28.3 $\mathrm{MPa}$ and 8.4 $\mathrm{MPa}$, respectively.

For the specimens subjected to axial compression, two layers of CFRP were used, while for those subjected to the protection of ICCP-SS, one layer was used. The CFRP consisted of carbon fiber bundles arranged in a bidirectional mesh, as shown in Figure 5a. The tensile strengths of the carbon fiber tows were tested in accordance with ASTM D4018 [20]. The test schematic diagram is shown in Figure $5 b$.

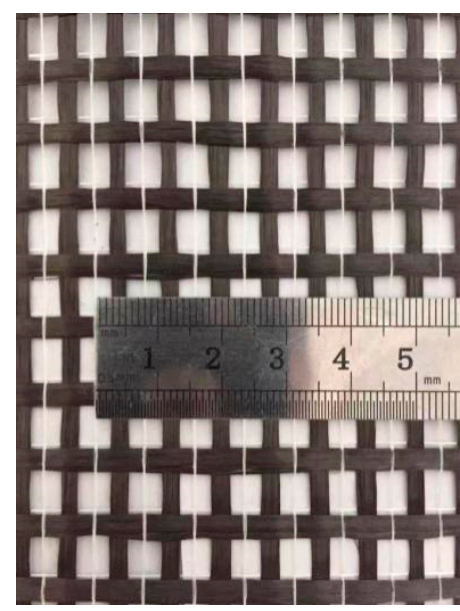

(a) Bidirectional fiber mesh

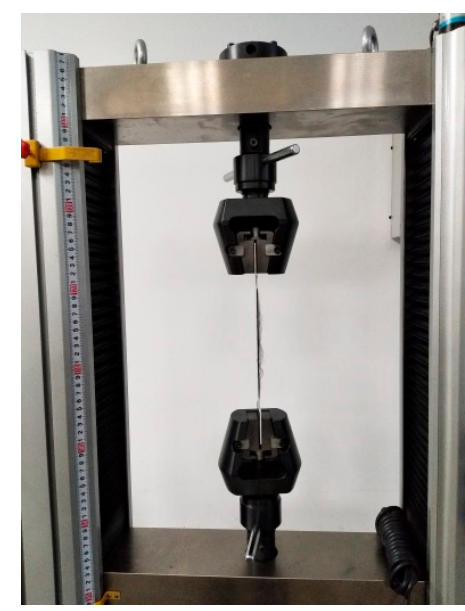

(b) Testing of mechanical properties

Figure 5. Bidirectional fiber mesh and mechanical properties test of carbon fiber bundles.

The material property test results of the CFRP material are shown in Table 4.

Table 4. Mechanical properties of the CFRP.

\begin{tabular}{cccc}
\hline$t / \mathbf{m m}$ & $E_{\mathrm{C}} / \mathbf{M P a}$ & $f_{\mathrm{u}-\mathrm{C}} / \mathrm{MPa}$ & $\varepsilon_{\mathrm{u}-\mathrm{C}}$ \\
\hline 0.046 & 181 & 2077 & $1.17 \%$ \\
\hline
\end{tabular}

Note: In Table $4, t$ is the calculated thickness (ratio of the area to the width of a single strand CFRP) of carbon fiber material; $E$ is the modulus of elasticity; $f_{\mathrm{u}-\mathrm{C}}$ is the ultimate tensile strength; $\varepsilon_{\mathrm{u}-\mathrm{C}}$ is the ultimate tensile strain.

\subsubsection{Tensile Properties of FRCM}

The size of test plates used for the tensile test of the FRCM is $550 \times 200 \times 10 \mathrm{~mm}$. CFRP is arranged with single/double layers in the cementitious material, and the test plate contained 5 bundles of tensile fibers within the width range. Three identical FRCM test plates were tested, the tensile behavior of the FRCM composite plates was obtained by tensile coupon tests in accordance with AC434 [21], and the average values of the measured tensile mechanical properties of FRCM plates are shown in Table 5. 
Table 5. Average values of the tensile mechanical properties of FRCM plates.

\begin{tabular}{cccccc}
\hline Layers of CFRP & $E^{*} / \mathrm{GPa}$ & $E_{\mathrm{F}} / \mathrm{GPa}$ & $\varepsilon_{\mathbf{t}}$ & $\varepsilon_{\mathbf{u}-\mathrm{F}}$ & $f_{\mathbf{u}-\mathrm{F}} / \mathbf{M P a}$ \\
\hline 1 & 6862.1 & 150.8 & $0.018 \%$ & $0.38 \%$ & 1539 \\
2 & 5656.0 & 77.3 & $0.012 \%$ & $1.29 \%$ & 1630 \\
\hline
\end{tabular}

Note: In Table $5, E^{*} \mathrm{~F}$ is the stiffness of FRCM before the cracking of cementitious material; $E_{\mathrm{F}}$ is the stiffness of FRCM after cracking of cementitious material; $\varepsilon_{t}$ is the strain of FRCM corresponding to cracking of cementitious material; $\varepsilon_{\mathrm{u}-\mathrm{F}}$ is the ultimate strain of FRCM; $f_{\mathrm{u}-\mathrm{F}}$ is the ultimate strength of FRCM.

\subsubsection{Loading of Axial Compression Test}

The axial compression test was carried out by displacement control with a speed of $0.3 \mathrm{~mm} / \mathrm{min}$. The test setup and schematic diagram of the axial compression test are shown in Figure 6.

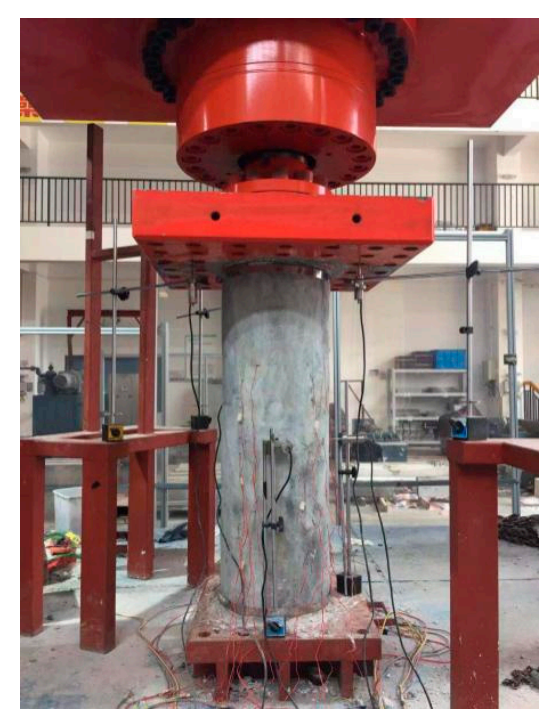

(a) Test setup

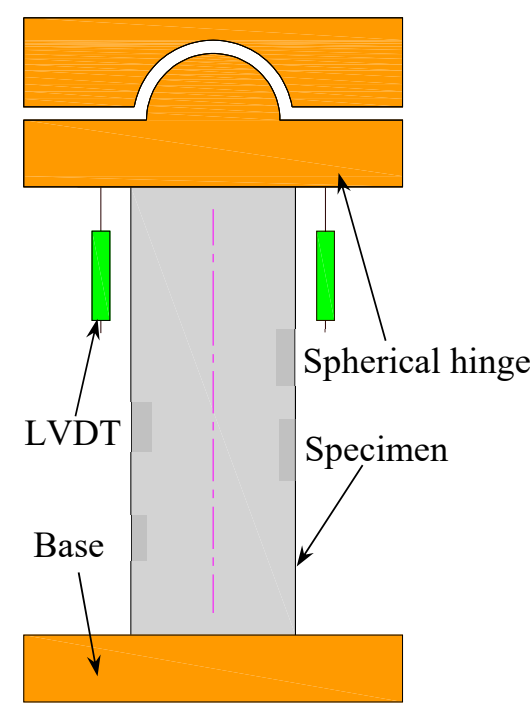

(b) Schematic diagram

Figure 6. Test setup and schematic diagram of the axial compression test.

\section{Test Results of Axial Compression Test}

\subsection{Failure Modes}

The failure modes of specimens subjected to axial compression are shown in Figure 7.

As can be seen in Figure 7, when the corrosion ratio of the specimens was lower than $5 \%$, for the specimens strengthened by FRCM (I-0-S and I-5-S), the outer appearance had no significant changes at the initial stage of loading; however, when the axial force reached $70 \%$ of the ultimate load, concrete cracks began to propagate from the end region; with the increase of axial load, these cracks gradually expanded to the middle section of the specimens, and part of the CFRP grid inside the FRCM began to rupture; when the ultimate load was reached, a large area of CFRP fracture was found in the end region of the specimens, as shown in Figure 7a. For the specimens with corrosion ratios lower than 5\% and without FRCM strengthening (specimens I- 0 and I-5), when the axial force reached 70\% of the ultimate load, numerous concrete cracks could be seen clearly in the end zones; when the ultimate load was reached, the concrete at the end of the specimens began to peel off, as shown in Figure $7 \mathrm{~b}$, following this, the specimens gradually lost their bearing capacity. 

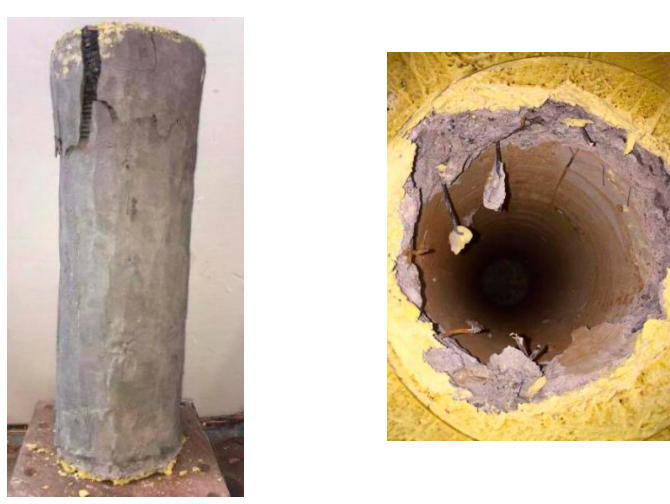

(a) Specimen I-5-S
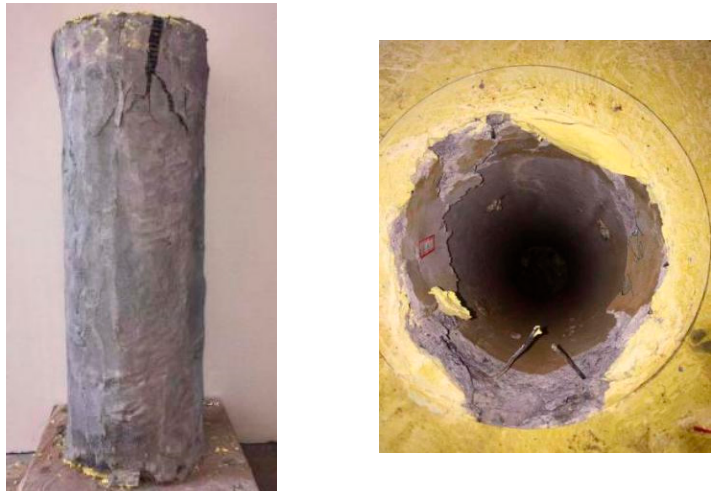

(c) Specimen I-15-S
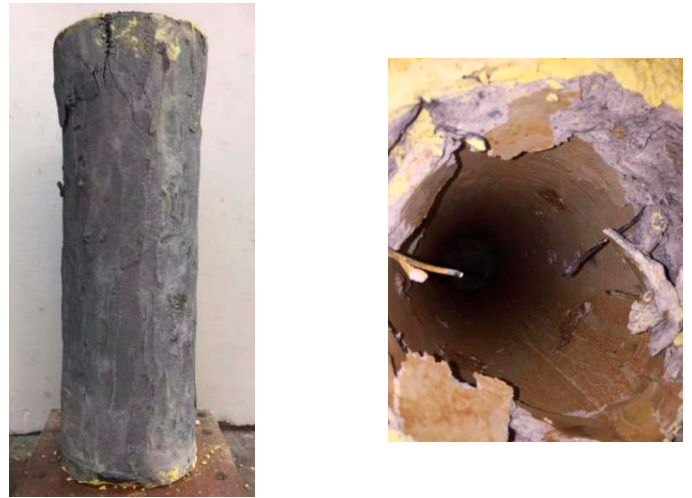

(e) Specimen I-25-S
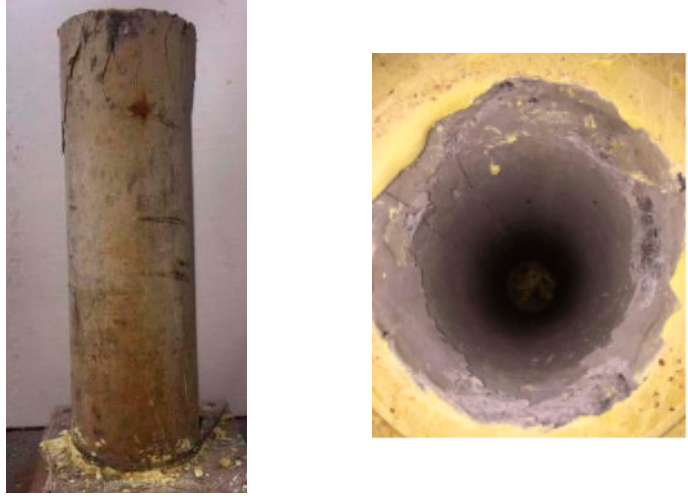

(b) Specimen I-5
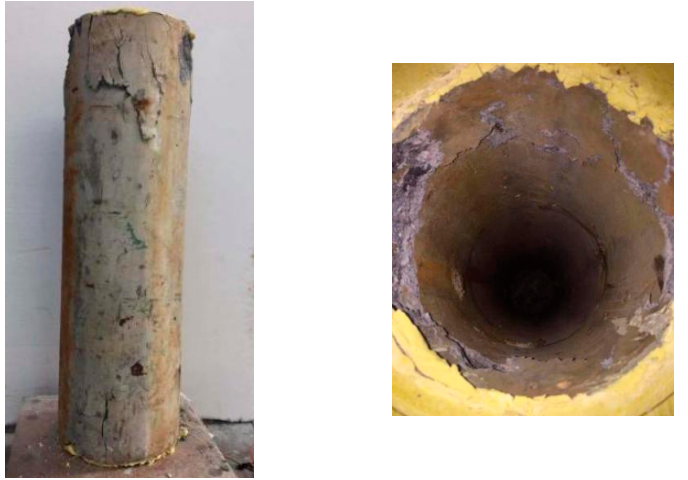

(d) Specimen I-15
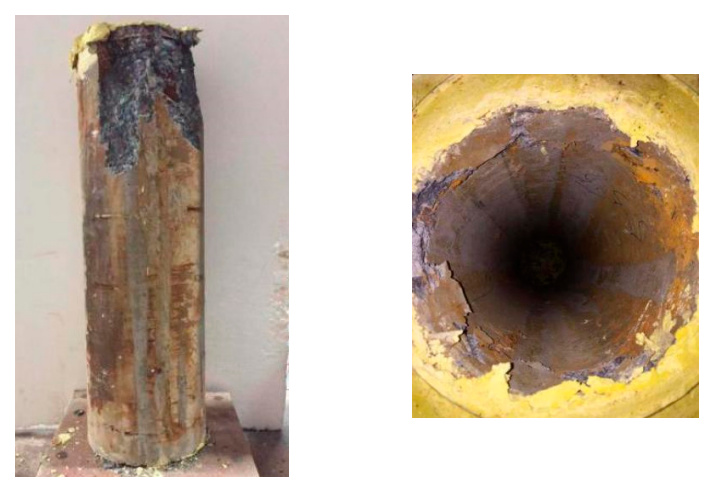

(f) Specimen I-25

Figure 7. Failure modes of the axial compression specimens.

For specimens with corrosion ratios higher than $5 \%$, the failure process of the strengthened specimens was similar to that for specimens with low corrosion ratios. In the specimens without FRCM strengthening, concrete cracks had already occurred at the end region when the axial force reached $30 \%$ of the ultimate load; this was mainly because the corrosion of the rebars caused expansion cracks inside the specimens before the test. These inner cracks extended rapidly to the surface upon being subjected to an axial load. When the ultimate load was reached, most of the concrete at the end region of the specimens had peeled off, as shown in Figure 7d,f; following this, the specimens rapidly lost their bearing capacity.

\subsection{Load-Displacement Curves}

The comparisons of load-displacement curves for strengthened and unstrengthened specimens with different corrosion ratios are shown in Figure 8. 


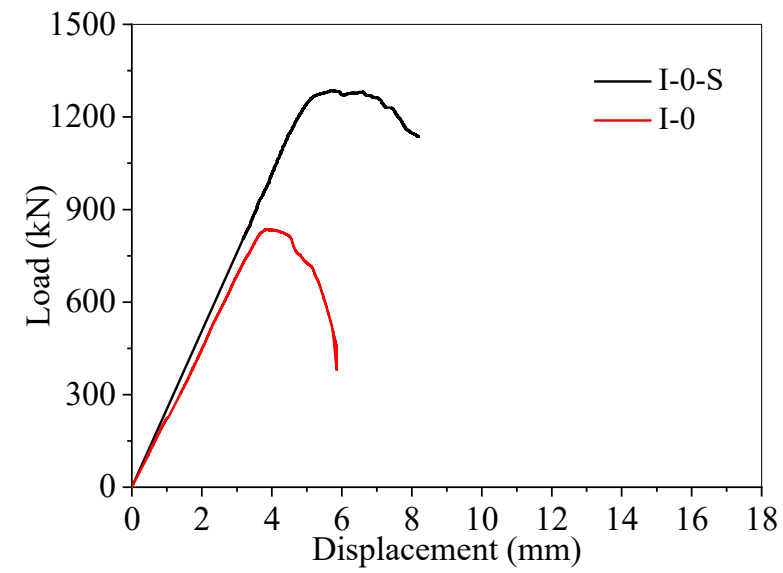

(a) Corrosion ratio of $0 \%$

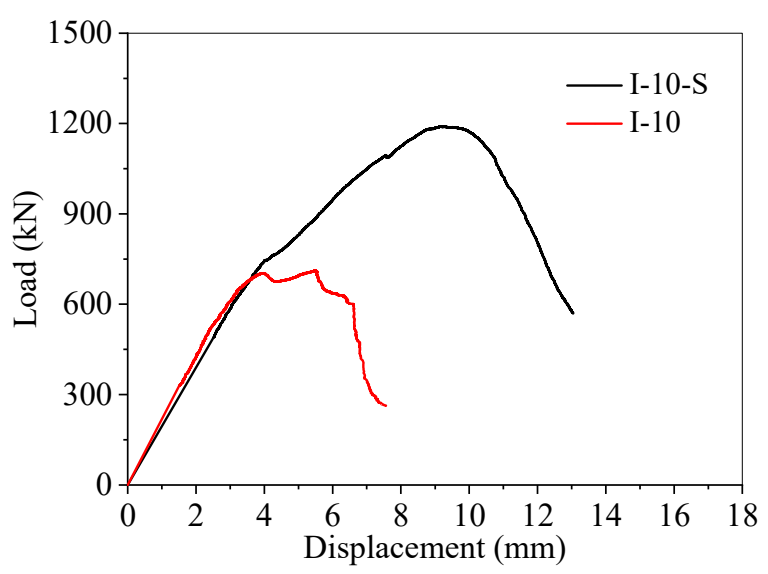

(c) Corrosion ratio of $10 \%$

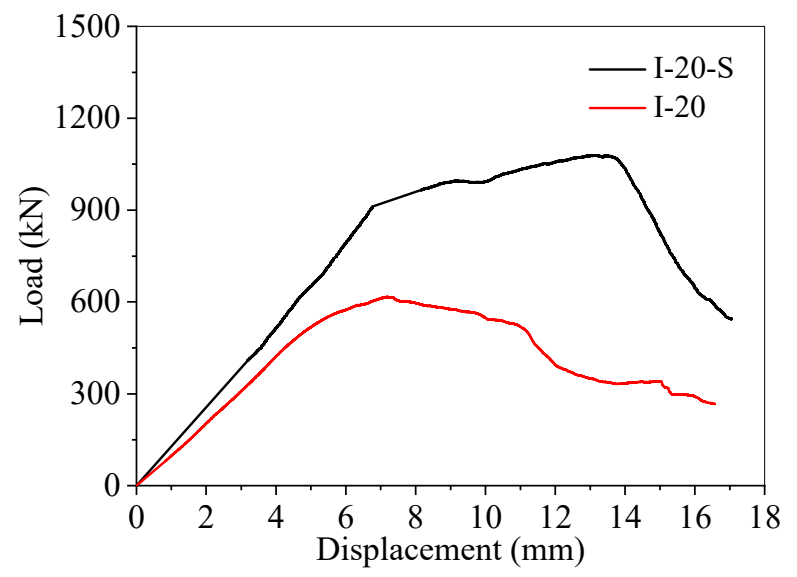

(e) Corrosion ratio of $20 \%$

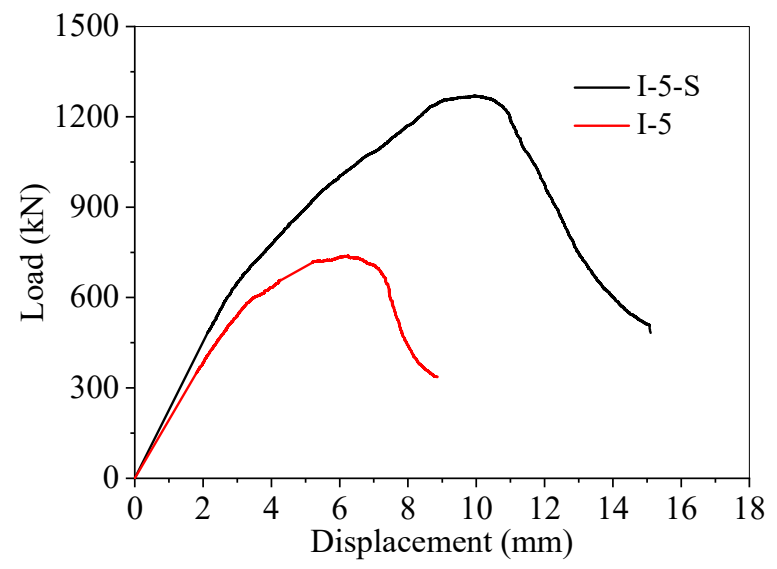

(b) Corrosion ratio of $5 \%$

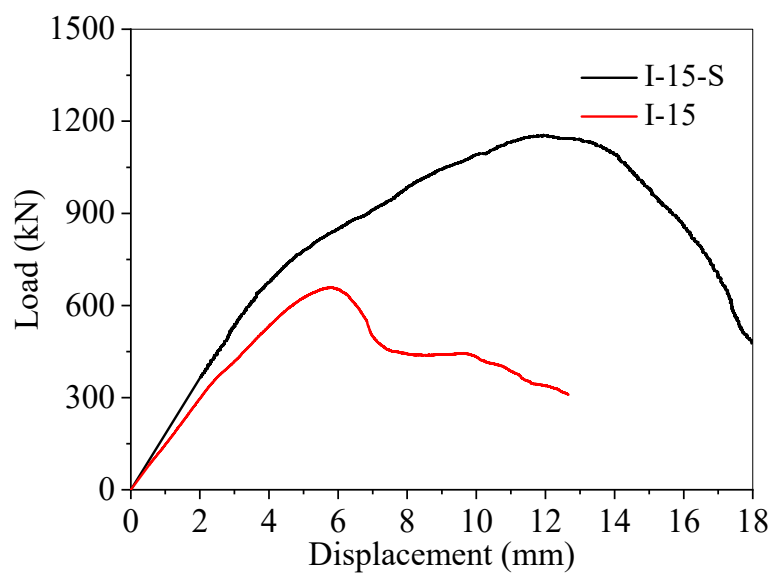

(d) Corrosion ratio of $15 \%$

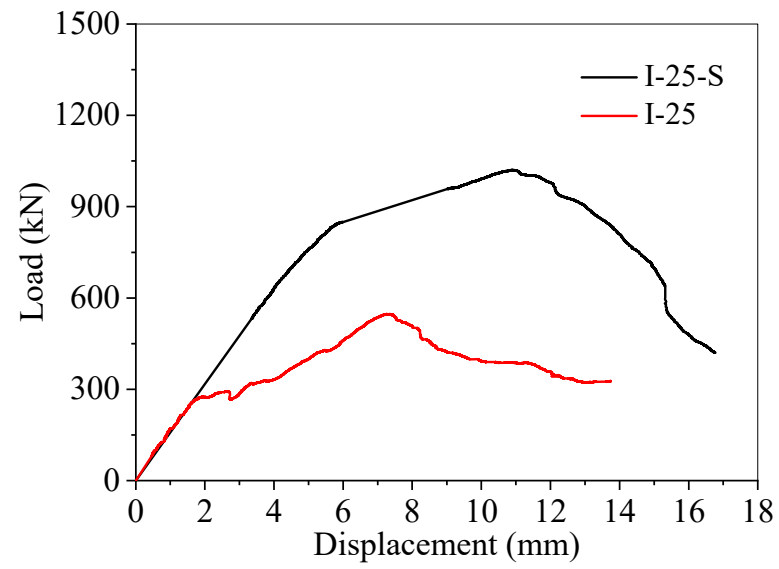

(f) Corrosion ratio of $25 \%$

Figure 8. Comparison of load-displacement curves of strengthened and unstrengthened specimens with different corrosion ratios.

As can be seen from Figure 8, the ultimate load of corroded specimens can be significantly increased by FRCM. Moreover, the axial displacement corresponding to the ultimate load of the strengthened specimens was larger than that of the unstrengthened specimens, especially for the specimens with higher corrosion ratios (corrosion ratio larger than $5 \%$ ). This is mainly because the FRCM could restrain the spalling of concrete, thus enabling 
the corroded specimens to bear load and deformation continuously. Additionally, the expansion of the concrete caused by the corrosion of rebars made the hoop effect of the confining FRCM more obvious; hence, the ductility of strengthened specimens with higher corrosion ratios was more obvious than in those with lower corrosion ratios.

\subsection{Ultimate Load}

Table 6 summarizes the ultimate load $N_{\mathrm{u}}$, ultimate compressive strength $\sigma_{\mathrm{u}}$, and ultimate strain $\varepsilon_{\mathrm{u} 0}$ of the axial compression specimens. The ultimate compressive strength $\sigma_{\mathrm{u}}$, is $N_{\mathrm{u}} / A$, where $A$ is the cross-sectional area of the specimen (for the strengthened specimen, $A$ includes the area of concrete, rebars, and cementitious material). The ultimate strain $\varepsilon_{\mathrm{u} 0}$ is the ratio between the axial displacement corresponding to the ultimate load and the height $L$ of the specimen.

Table 6. Test results of the axial compression specimens.

\begin{tabular}{ccccc}
\hline Specimen & Corrosion Ratio $\eta$ & $N_{\mathbf{u}} / \mathbf{k N}$ & $\sigma_{\mathbf{u}} / \mathbf{M P a}$ & $\varepsilon_{\mathbf{u} \mathbf{0}} / \%$ \\
\hline I1-0-S & $0 \%$ & 1285.8 & 21.3 & 0.58 \\
I1-5-S & $5 \%$ & 1270.0 & 21.1 & 0.96 \\
I1-10-S & $10 \%$ & 1156.9 & 19.2 & 0.99 \\
I1-15-S & $15 \%$ & 1134.5 & 18.8 & 1.21 \\
I1-20-S & $20 \%$ & 1079.2 & 17.9 & 1.35 \\
I1-25-S & $25 \%$ & 1020.6 & 16.9 & 1.13 \\
\hline I1-0 & $0 \%$ & 835.9 & 16.5 & 0.38 \\
I1-5 & $5 \%$ & 738.6 & 14.6 & 0.54 \\
I1-10 & $10 \%$ & 711.8 & 14.1 & 0.49 \\
I1-15 & $15 \%$ & 659.0 & 13.0 & 0.60 \\
I1-20 & $20 \%$ & 612.1 & 12.1 & 0.74 \\
I1-25 & $25 \%$ & 547.6 & 10.8 & 0.76 \\
\hline
\end{tabular}

It can be seen from Table 6 that the ultimate load (or ultimate stress) of the tested specimens decreases with the increase of corrosion ratio, whether the specimens were strengthened or not. The main reason for this is that the corrosion products produced by rebars will cause expansion cracks within the concrete, and a higher corrosion ratio will lead to increased damage of the internal structure of the concrete. Hence, the ultimate load (or ultimate stress) of the specimens will decrease with the increase of corrosion ratio. For specimens with corrosion ratios of $0 \%, 5 \%, 10 \%, 15 \%, 20 \%$, and $25 \%$, the ultimate loads of the strengthened specimens are $53.8 \%, 71.9 \%, 62.5 \%, 72.2 \%, 76.3 \%$, and $86.4 \%$ higher than that of the unstrengthened specimens, respectively, which indicates that the enhancement effect of FRCM on ultimate load is more pronounced for specimens with higher corrosion ratios. This decrease of ultimate load with respect to an increasing corrosion ratio occurred at a different rate in the strengthened and unstrengthened specimens. Those strengthened by FRCM experienced a slower rate of bearing capacity reduction caused by the rebar corrosion.

It can be seen from Table 6 that the ultimate strain increases with the increase of corrosion ratio, whether the specimens are strengthened or not. This is largely because the expansion cracks in the concrete, caused by the corroding rebars, results in a decrease in rigidity. Consequently, specimens with higher corrosion ratios experienced a greater deformation when loaded.

\subsection{Calculation of Ultimate Load}

When RC columns strengthened by FRCM are subjected to axial compression, the axial loads are borne by the concrete, longitudinal rebars and cementitious material of FRCM. For the RC columns whose rebars are corroded, the strength of the longitudinal rebars will be weakened [22]. According to research results proposed by Sun et al. [23], the 
relationship between the ratio of $f_{\mathrm{y}}{ }^{*}$ (yield strength of corroded rebars) to $f_{\mathrm{y}}$ (yield strength of non-corroded rebars) and the corrosion ratio $\eta$ can be expressed as follows:

$$
f_{\mathrm{y}}{ }^{*} / f_{\mathrm{y}}=1-1.1 \eta
$$

According to the analysis above, the ultimate load of corroded RC columns strengthened by FRCM can be expressed as follows:

$$
N=f_{\mathrm{cc}} A_{\mathrm{c}}+f_{\mathrm{y}}{ }^{*} A_{\mathrm{s}}+f_{\mathrm{m}} A_{\mathrm{m}}
$$

In Equation (2), $f_{\mathrm{cc}}$ is the compressive strength of the core concrete in the strengthened columns, and $A_{\mathrm{c}}$ is the cross-sectional area of the core concrete; $A_{\mathrm{s}}$ is the cross-sectional area of the rebars before corrosion; $f_{\mathrm{m}}$ is the compressive strength of the cementitious material in the FRCM, and $A_{\mathrm{m}}$ is the cross-sectional area of the cementitious material.

According to the test results and Equation (2), the calculated core concrete compressive strengths of the strengthened specimens, $f_{\mathrm{cc}}$, and of the unstrengthened specimens, $f_{\mathrm{co}}$, are shown in Table 7.

Table 7. Compressive strength of core concrete of tested specimens.

\begin{tabular}{ccccccc}
\hline Specimen & $\eta$ & $f_{\text {cc }} / \mathbf{M P a}$ & $f_{\text {co }} / \mathbf{M P a}$ & $\beta_{\rho}$ & $K_{\eta \text {-Test }}$ & $K_{\eta \text {-Design }}$ \\
\hline I-0-S & $0 \%$ & 13.45 & & 1.35 & 1.00 & 1.00 \\
I-5-S & $5 \%$ & 13.51 & & 1.61 & 1.19 & 1.04 \\
I-10-S & $10 \%$ & 11.62 & & 1.42 & 1.05 & 1.08 \\
I-15-S & $15 \%$ & 11.54 & & 1.53 & 1.14 & 1.13 \\
I-20-S & $20 \%$ & 10.81 & & 1.56 & 1.15 & 1.17 \\
I-25-S & $25 \%$ & 10.01 & & 1.66 & 1.23 & 1.21 \\
\hline I-0 & $0 \%$ & & 9.95 & & & \\
I-5 & $5 \%$ & & 8.37 & & & \\
I-10 & $10 \%$ & & 8.21 & & & \\
I-15 & $15 \%$ & & 7.52 & & & \\
I-20 & $20 \%$ & & 6.95 & & & \\
I-25 & $25 \%$ & & 6.03 & & & \\
\hline
\end{tabular}

Note: In Table $7, \beta_{\rho}$ is the ratio of $f_{\mathrm{cc}}$ and $f_{\mathrm{co}}$, i.e., $\beta_{\rho}=f_{\mathrm{cc}} / f_{\mathrm{co}} ; K_{\eta}$-Test is the ratio of $\beta_{\rho}$ (with different corrosion ratios) and $\beta_{\rho 0}$ (with the corrosion ratio of $0 \%$ ), i.e., $K_{\eta}$-Test $=\beta_{\rho} / \beta_{\rho 0} ; K_{\eta}$-Design is calculated based on the fitting equation of Equation (3).

According to the test results showed in Table 7, linear regression was used to fit $K_{\eta \text {-Test }}$ values to different corrosion ratios $\eta$. It should be noted that the fitted results have excluded the specimen I-5-S, because the results indicated that a higher corrosion ratio accompanied a lower concrete compressive strength $f_{\mathrm{cc}}$, which is inconsistent with the overall trend of test results. Therefore, the test results of specimen I-5-S cannot be used to accurately reflect real-life situations, so it is eliminated. In addition, the fitting curve of $K_{\eta \text {-Test }}$ was ensured to pass through the point $(0,1)$, because for the specimen with corrosion ratio $\eta$ equal to 0 , the core concrete compressive strength remains unchanged. The relationship between $K_{\eta \text {-Design }}$ and corrosion ratio $\eta$ obtained by the fitting result is expressed as follows (corresponding $\mathrm{R}^{2}=0.936$ ):

$$
K_{\eta \text {-Design }}=1+0.8407 \eta
$$
Table 7.

The calculated values of $K_{\eta \text {-Design, }}$ according to the fitted equation are shown in

\section{Effect of ICCP-SS on the Distribution Laws of $\mathrm{Cl}^{-}$in $\mathrm{RC}$ Hollow Columns}

In this paper, $12 \mathrm{RC}$ hollow columns were protected via ICCP-SS. After the charging process, a core was taken from each specimen and then milled, the diameter of the cored concrete was $90 \mathrm{~mm}$. Additionally, it was ensured that the rebars were located in the middle of the specimen when drilling. The $\mathrm{Cl}^{-}$content at numerous points in the core 
sample was measured by potentiometric titration. The drilling process and the core sample taken from the tested columns are shown in Figure 9.

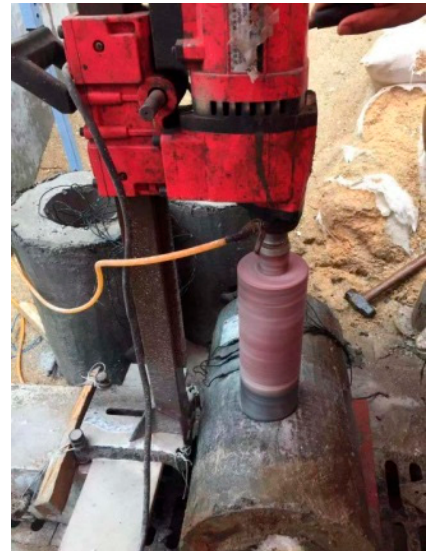

(a) Core drilling (Specimen IC-4-S)

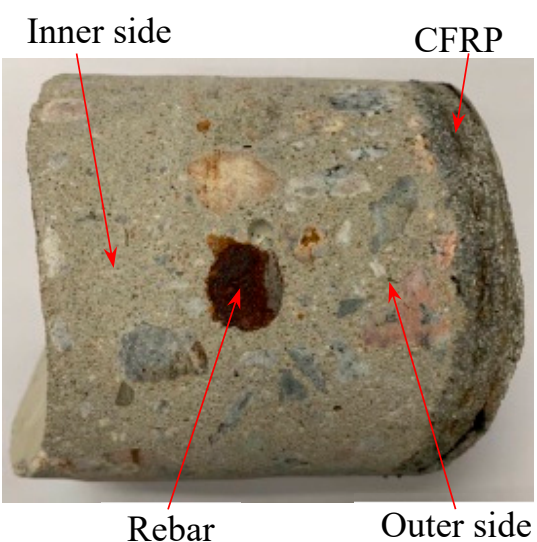

(b) Core sample (Specimen IC-4-S)

Figure 9. Drilling process and the core sample.

The grinding operation was carried out according to the positions marked with different color bands and shown in Figure 10. The specific sampling process was as follows: (1) Along the positive direction (i.e., the outer side), the concrete located in areas 1, 2, 3, 4, 5, 6, 7, and 8, showed in Figure 10, was sampled, and the center of these areas were 7, 9, 13, $17,21,25,29$, and $33 \mathrm{~mm}$ from the center of the rebar, respectively; (2) samples were taken from either side of the CFRP, areas 9 and 10, to obtain the distribution of $\mathrm{Cl}^{-}$across the FRCM layer; (3) Along the negative direction (i.e., the inner side), the concrete located in areas 1, 2, 3, 4, 5, 6, 7, 8, and 9, shown in Figure 10, was sampled, and the center of these areas were $-7,-9,-11,-14,-18,-22,-26,-29$, and $-32 \mathrm{~mm}$ from the center of the rebar, respectively.

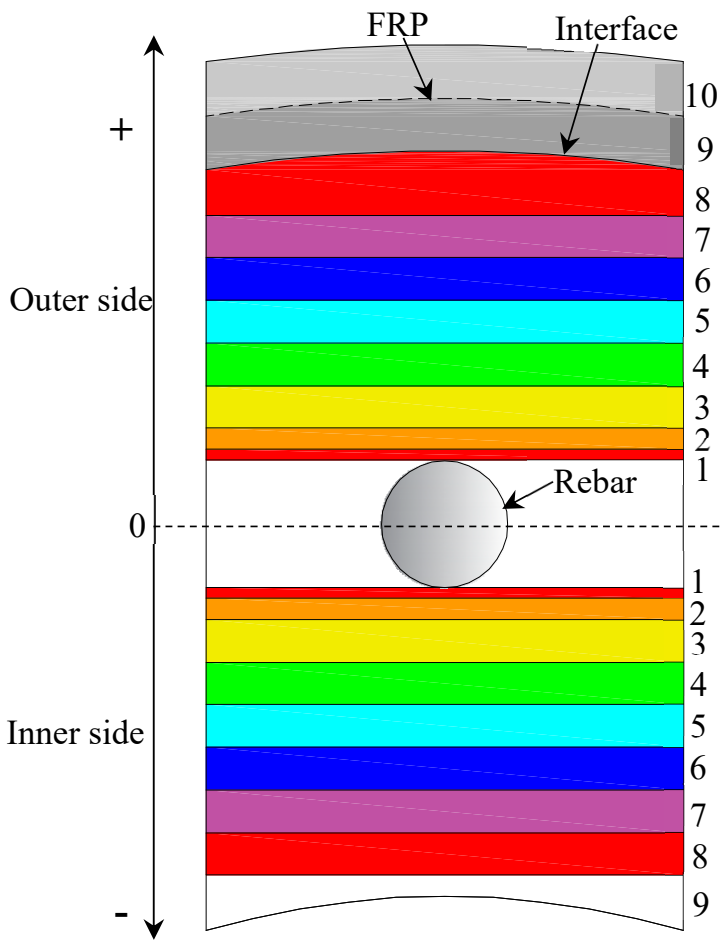

Figure 10. Sampling positions of grinding powders. 


\subsection{Influence of Conduction Time}

According to Section 2.2, the groups of specimens shown in Table 2 were protected by ICCP for 4,7 , and 10 months with current densities of 20 and $60 \mathrm{~mA} / \mathrm{m}^{2}$. Through the potentiometric titration method, the influence of different conduction times, as well as the inclusion of additional salt, on the distribution of $\mathrm{Cl}^{-}$through the depth of the concrete is shown in Figure 11. The location of the rebar and the interface between the concrete and the FRCM layer are also indicated for comparison.

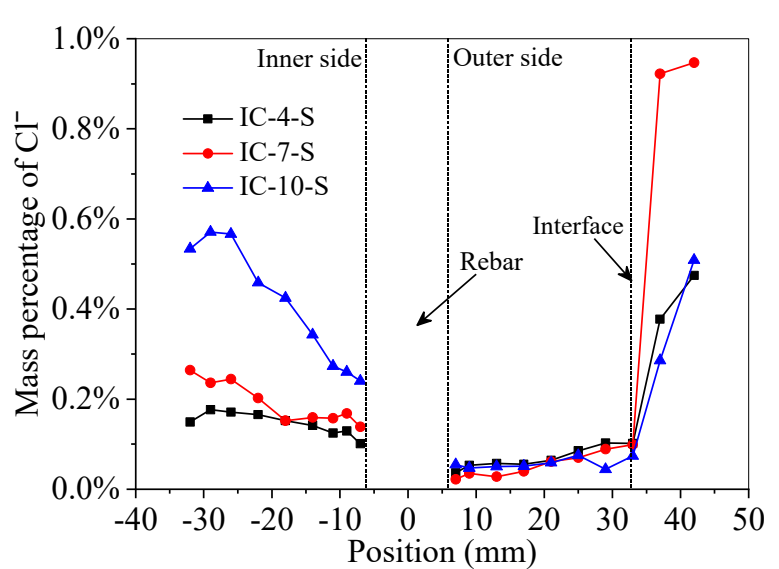

(a) $\mathrm{I}=20 \mathrm{~mA} / \mathrm{m}^{2}$, without $\mathrm{Cl}^{-}$

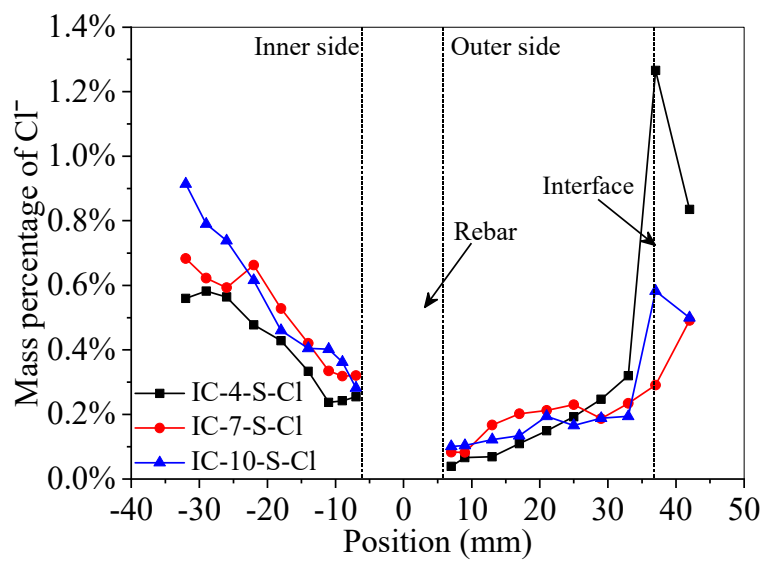

(c) $\mathrm{I}=20 \mathrm{~mA} / \mathrm{m}^{2}$, with $\mathrm{Cl}^{-}$

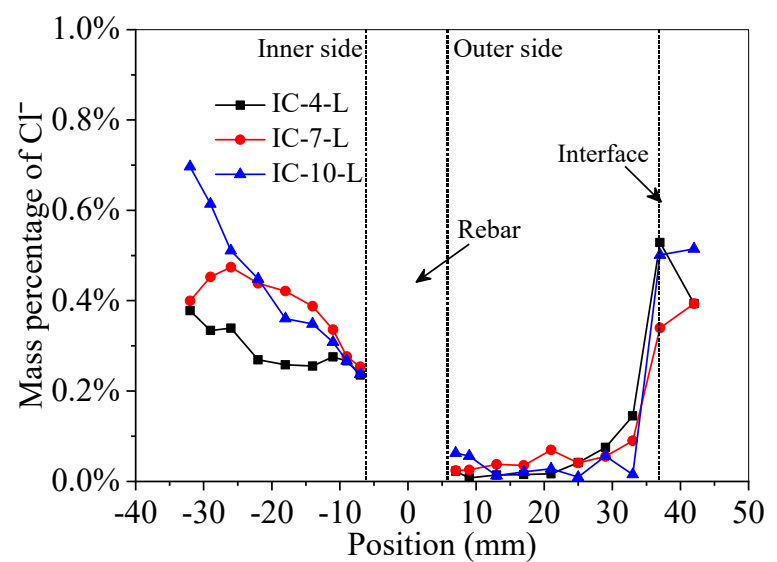

(b) $\mathrm{I}=60 \mathrm{~mA} / \mathrm{m}^{2}$, without $\mathrm{Cl}^{-}$

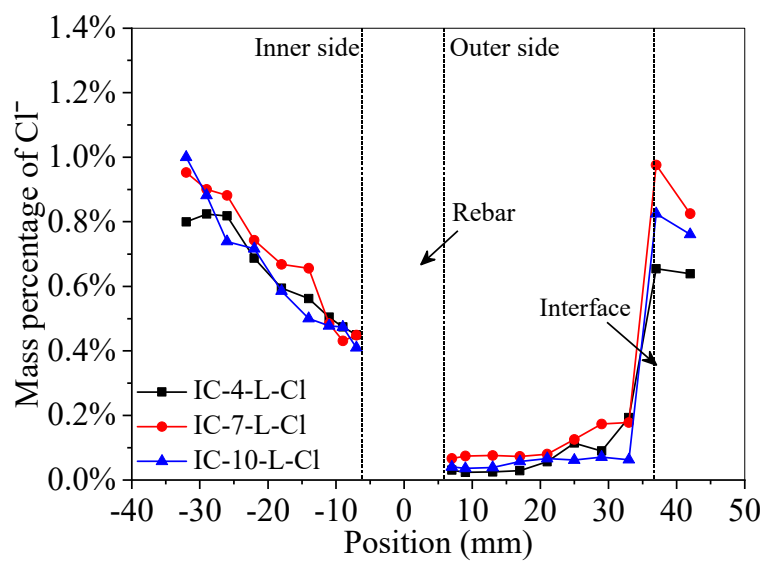

(d) $\mathrm{I}=60 \mathrm{~mA} / \mathrm{m}^{2}$, with $\mathrm{Cl}^{-}$

Figure 11. Influence of different conduction times and salt addition on the distribution of $\mathrm{Cl}^{-}$content on both sides of rebars.

As can be seen from Figure 11, for specimens without salt addition and with protection current densities of $20 \mathrm{~mA} / \mathrm{m}^{2}$ (Figure 11a) and $60 \mathrm{~mA} / \mathrm{m}^{2}$ (Figure 11b), the following patterns can be found. (1) The $\mathrm{Cl}^{-}$content located toward the inner side of the rebar $(x<0 \mathrm{~mm})$ is generally higher than that of the outer side $(x>0 \mathrm{~mm})$. This is due to the fact that the chlorine salt mainly accumulated in the surface material near the cavity, where the salt was added, and the concentration (i.e., the concentration of the acid-soluble chloride, and the same as the following) of $\mathrm{Cl}^{-}$gradually decreases as it diffused further into the concrete; hence, the $\mathrm{Cl}^{-}$content near the inner surface of the core is higher. (2) $\mathrm{The}^{-}$ content gradually decreases from the cavity surface to the surface of the rebars, and this trend is more obvious when the conduction time is longer. (3) The $\mathrm{Cl}^{-}$content of each specimen decreases continuously when getting closer to the rebars, and the discrepancy of $\mathrm{Cl}^{-}$content between each specimen also decreases continuously, especially for the region near the outer surface of the rebar. In addition, the $\mathrm{Cl}^{-}$content near the outer side of the rebar is always larger than that of the inner side. (4) Around the interface between the FRCM and the concrete, the $\mathrm{Cl}^{-}$content increases significantly when comparing a low 
current density $\left(\mathrm{I}=20 \mathrm{~mA} / \mathrm{m}^{2}\right)$ to a high current density $\left(\mathrm{I}=20 \mathrm{~mA} / \mathrm{m}^{2}\right)$. This shows that the impressed current causes the $\mathrm{Cl}^{-}$near the rebars to move toward the anode; i.e., the $\mathrm{Cl}^{-}$moves to the vicinity of the CFRP.

For specimens with salt addition and with protection current densities of $20 \mathrm{~mA} / \mathrm{m}^{2}$ (Figure 11c) and $60 \mathrm{~mA} / \mathrm{m}^{2}$ (Figure 11d), the development of the $\mathrm{Cl}^{-}$content is consistent with conclusion (1) of the specimens without salt addition. However, compared with the above conclusion (2), for the specimens with additional salt, the influence of conduction time on the development trend of the $\mathrm{Cl}^{-}$content from the cavity surface to the vicinity of rebars is not as obvious. The $\mathrm{Cl}^{-}$content close to the rebar is also lower than in the other regions for the salt-added specimens, and the difference between the inner and outer sides of the rebar is also obvious, which is consistent with conclusion (3). Similarly, the $\mathrm{Cl}^{-}$ content in the vicinity of the CFRP also increased significantly for the salt-added specimens, which is consistent with the above conclusion (4).

Furthermore, it can be found from Figure 11 that the difference in $\mathrm{Cl}^{-}$content between the inner and outer sides of the rebar is more obvious for specimens with higher current densities, regardless of whether the conduction time was long or short, and irrespective of whether the specimens had salt added or not. This phenomenon is due firstly to the absorption effect the electric field has on $\mathrm{Cl}^{-}$in the cavity, and secondly the barrier the rebar formed to retard the migration process of the $\mathrm{Cl}^{-}$, thus causing a clear difference in $\mathrm{Cl}^{-}$content either side of the rebar. Around the vicinity of the rebar, the $\mathrm{Cl}^{-}$content was at a minimum, less than in other regions in the corresponding direction, even if the rebar blocks the migration of $\mathrm{Cl}^{-}$to a certain extent. This demonstrates that the impressed current can reduce the $\mathrm{Cl}^{-}$content near the rebar, and it proves that ICCP can play a protective role for the reinforcement.

\subsection{Influence of Current Density}

Based on the potentiometric titration measurements, the influence of different current densities on the distribution of $\mathrm{Cl}^{-}$content, with and without the addition of salt, and for conduction times of 4, 7, and 10 months, is shown in Figure 12.

As can be seen from Figure 12, for specimens without salt addition and with a conduction time of 4 months (Figure 12a) and 7 months (Figure 12b): On the inner side of the rebar $(\mathrm{x}<0 \mathrm{~mm})$, a larger current density induces a higher $\mathrm{Cl}^{-}$content, but this effect is less notable with an increase of conduction time. For example, in the specimen with a conduction time of 10 months, shown in Figure 12c, the current densities have little influence on the $\mathrm{Cl}^{-}$content on the inner side of the rebar. For the outer side of the rebar $(x>0 \mathrm{~mm})$, the $\mathrm{Cl}^{-}$content remained at a lower level than the inner side for specimens with different conduction times, and there was no obvious change of the $\mathrm{Cl}^{-}$content even when a larger current density was applied. This is mainly because the $\mathrm{Cl}^{-}$content is relatively low for specimens without salt addition, and the electric field formed by any current can successfully migrate most of the $\mathrm{Cl}^{-}$to the anode. Around the interface between the FRCM and the concrete, the $\mathrm{Cl}^{-}$content increases significantly, showing that the impressed current causes the $\mathrm{Cl}^{-}$to move toward the anode.

For the salt-added specimens (Figure $12 \mathrm{~d}-\mathrm{f}$ ), the influence of current density on the $\mathrm{Cl}^{-}$content on the inner side of rebars $(x<0 \mathrm{~mm})$ is similar, except that the overall $\mathrm{Cl}^{-}$ content of the salt-added specimens is higher relative to the specimens without salt addition. Thus, the $\mathrm{Cl}^{-}$content on either side of the rebar is higher than that of the specimens without salt addition. It is worth noting that on the outer side of the rebar $(x>0 \mathrm{~mm})$, a relatively lower $\mathrm{Cl}^{-}$content is obtained by applying a larger current density, which is different from the distribution seen on the inner side. This is mainly because the $\mathrm{Cl}^{-}$content of the salt-added specimens is relatively higher than the specimens without, and the electric field formed by a smaller current density is not sufficient to migrate most of the $\mathrm{Cl}^{-}$to the anode. In addition, for the surrounding cementitious material, the $\mathrm{Cl}^{-}$content in the FRCM also increased significantly whether the specimens had salt added or not, and this 
phenomenon also reinforces that the effect of impressed current causes the $\mathrm{Cl}^{-}$near the rebar to move to the anode.

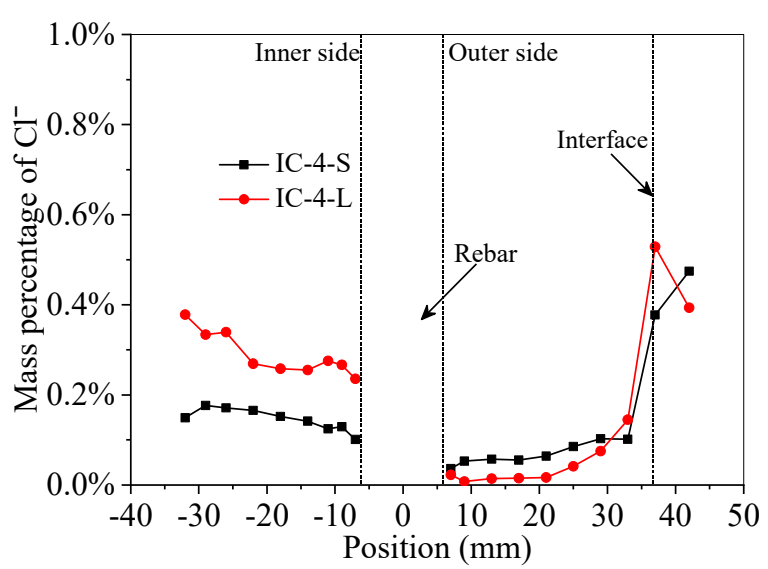

(a) Conduction time of 4 months, without $\mathrm{Cl}^{-}$

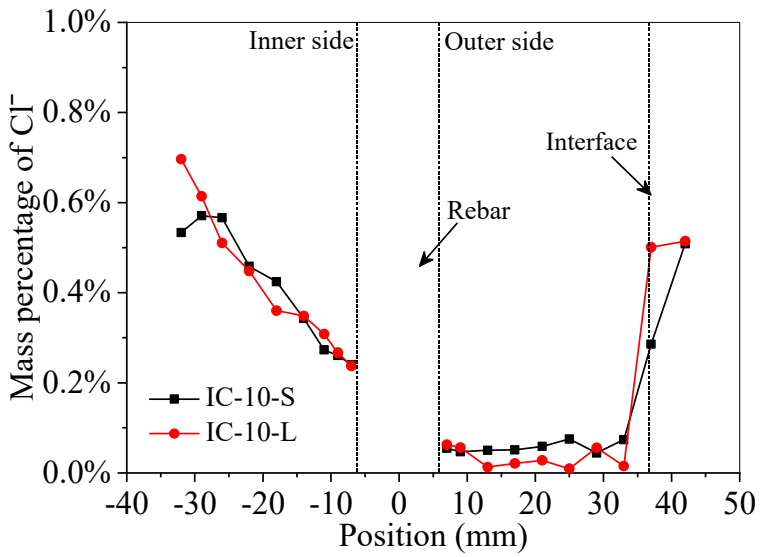

(c) Conduction time of 10 months, without $\mathrm{Cl}^{-}$

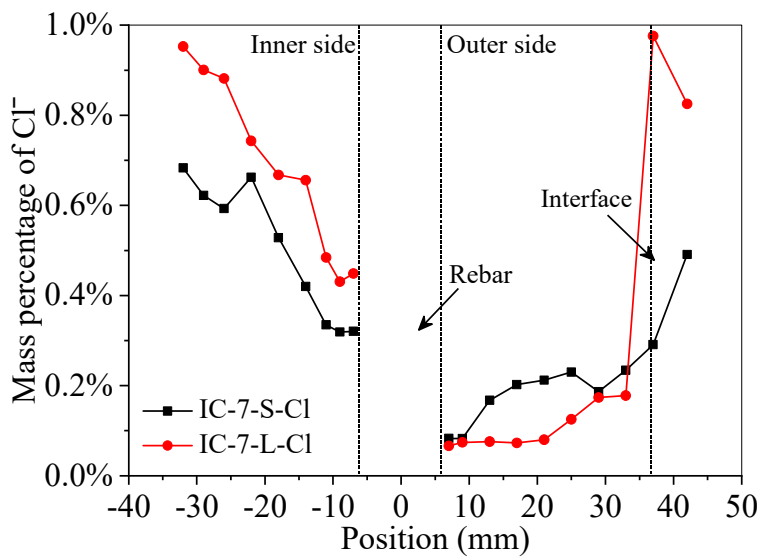

(e) Conduction time of 7 months, with $\mathrm{Cl}^{-}$

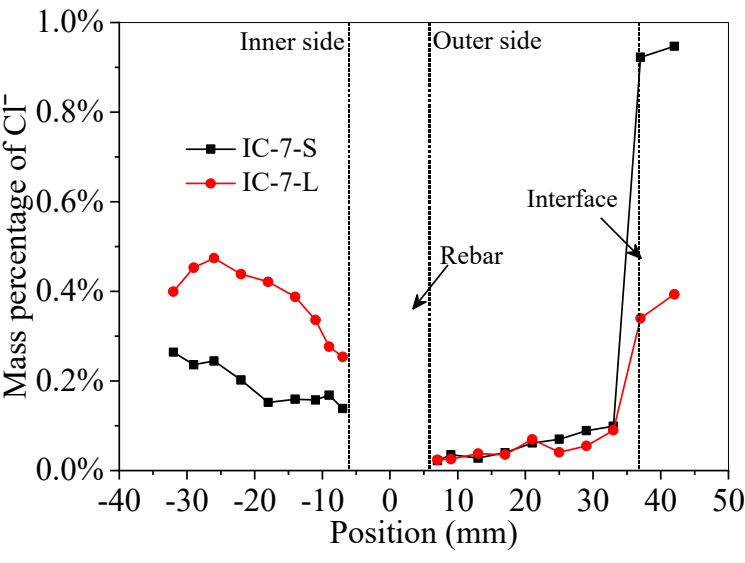

(b) Conduction time of 7 months, without $\mathrm{Cl}^{-}$

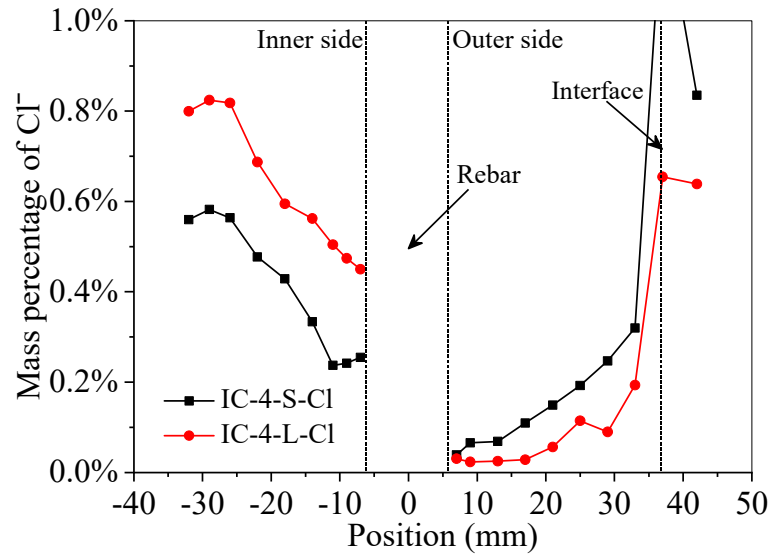

(d) Conduction time of 4 months, with $\mathrm{Cl}^{-}$

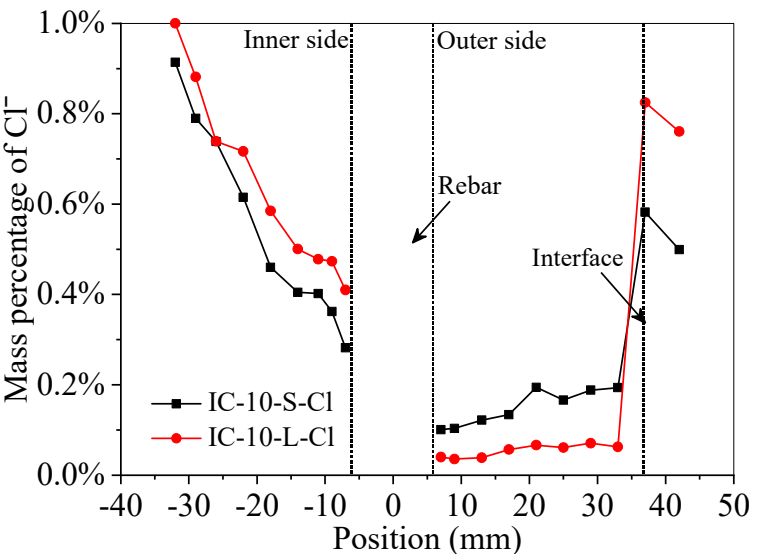

(f) Conduction time of 10 months, with $\mathrm{Cl}^{-}$

Figure 12. Influence of different current densities on the $\mathrm{Cl}^{-}$content at both sides of rebars.

Overall, in the regions on the inner side of the rebar $(x<0 \mathrm{~mm})$, a larger current density usually lead to higher $\mathrm{Cl}^{-}$content, which may have a negative impact on rebars; however, this negative impact gradually diminished with the increase of conduction time. In the regions on the outer side of the rebar $(x>0 \mathrm{~mm})$, a larger current density usually lead to a better migration effect on $\mathrm{Cl}^{-}$; that is, a larger current density plays a positive role for the protection of rebars. 


\subsection{Influence of Salt Addition}

The influence of salt addition on the distribution of $\mathrm{Cl}^{-}$content in both sides of rebars is shown in Figure 13, for specimens protected by ICCP for 4, 7, and 10 months and with current densities of 20 and $60 \mathrm{~mA} / \mathrm{m}^{2}$.

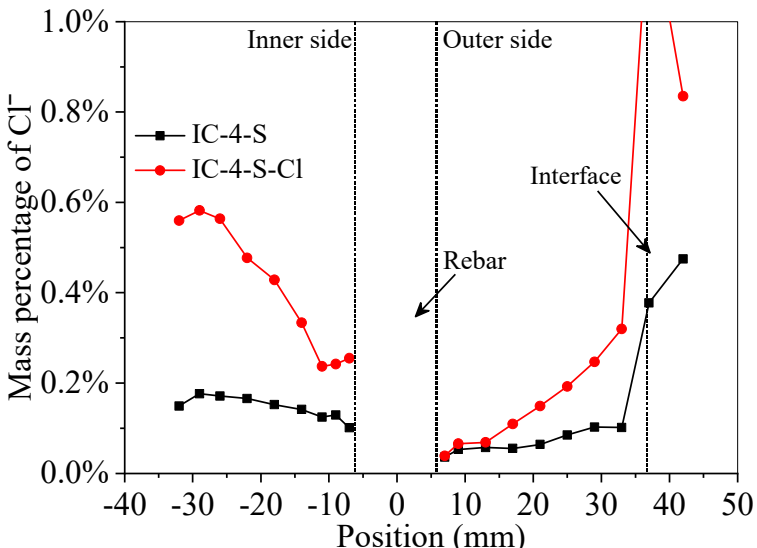

(a) Conduction time of 4 months, $\mathrm{I}=20 \mathrm{~mA} / \mathrm{m}^{2}$

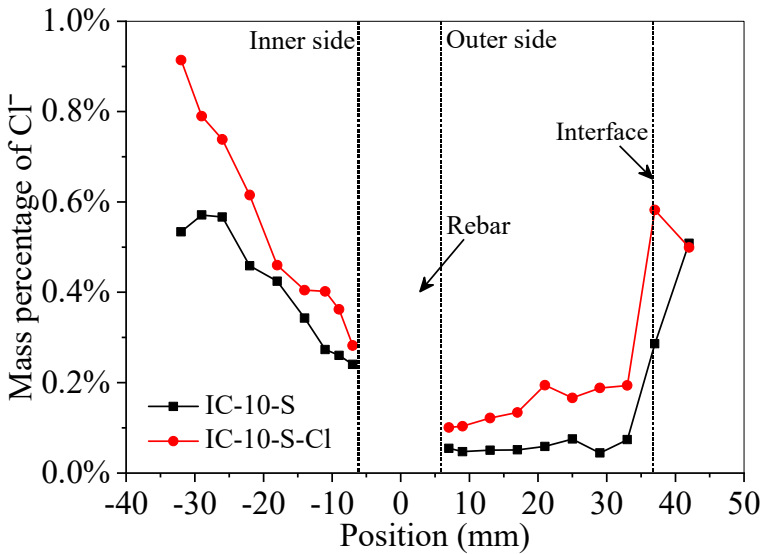

(c) Conduction time of 10 months, $\mathrm{I}=20 \mathrm{~mA} / \mathrm{m}^{2}$

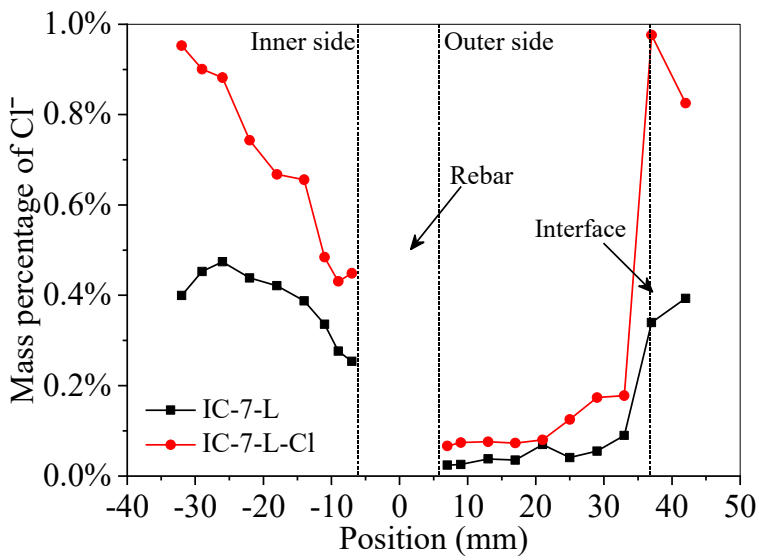

(e) Conduction time of 7 months, $\mathrm{I}=60 \mathrm{~mA} / \mathrm{m}^{2}$

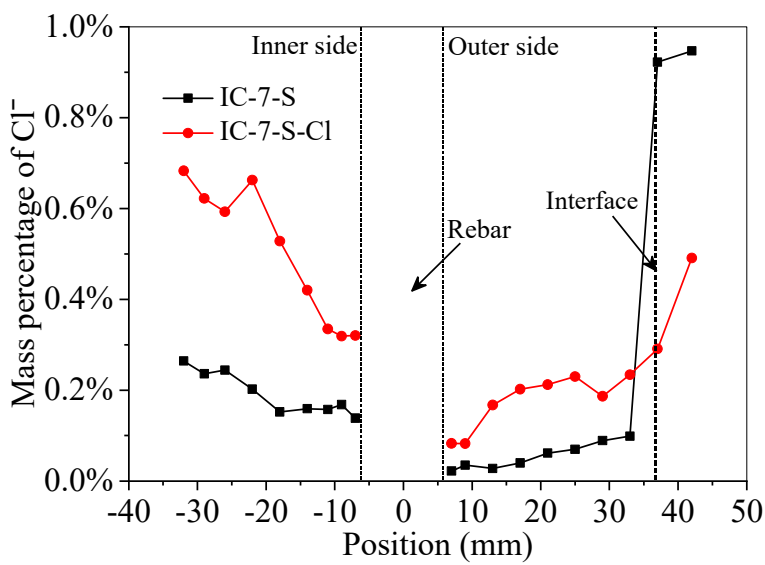

(b) Conduction time of 7 months, $\mathrm{I}=20 \mathrm{~mA} / \mathrm{m}^{2}$

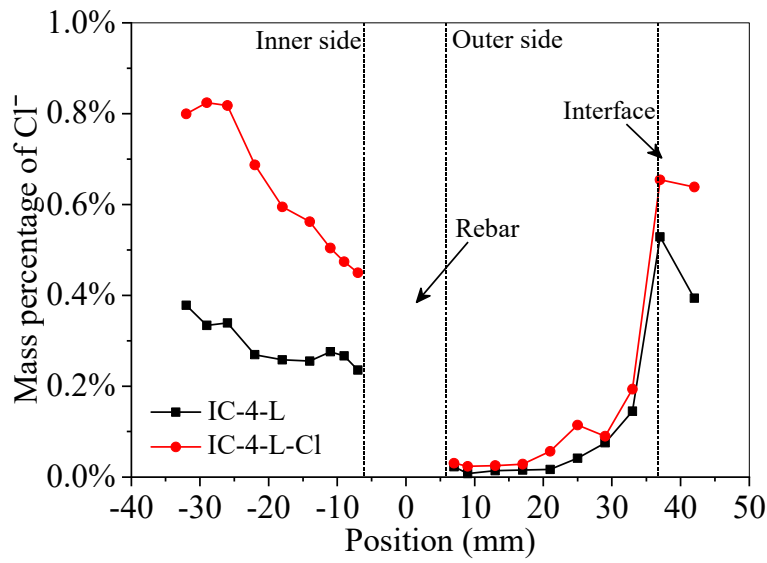

(d) Conduction time of 4 months, $\mathrm{I}=60 \mathrm{~mA} / \mathrm{m}^{2}$

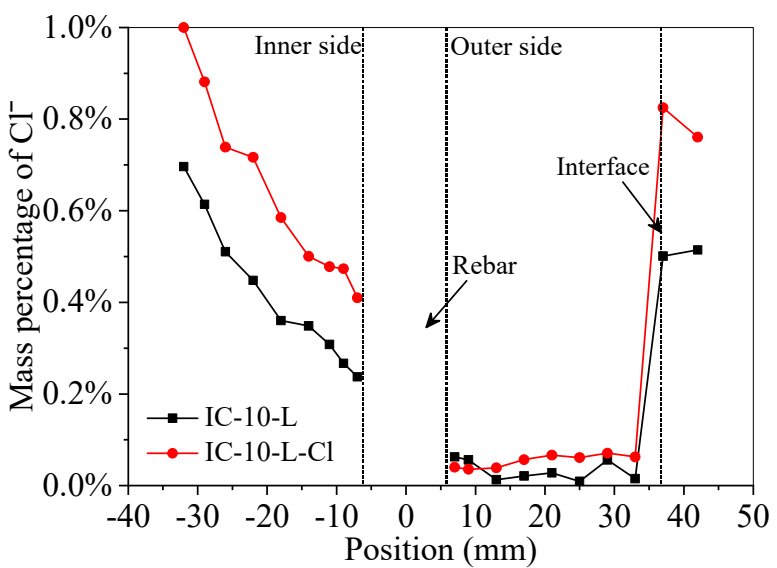

(f) Conduction time of 10 months, I $=60 \mathrm{~mA} / \mathrm{m}^{2}$

Figure 13. Influence of salt addition or not on distribution of $\mathrm{Cl}^{-}$content in both sides of rebars.

As can be seen from Figure 13, for specimens conducted with a current density of $20 \mathrm{~mA} / \mathrm{m}^{2}$ (Figure $13 \mathrm{a}-\mathrm{c}$ ), the overall $\mathrm{Cl}^{-}$content of the specimens with salt addition is 
higher than that of the specimens without salt addition, whether on the inner $(x<0 \mathrm{~mm})$ or outer $(x>0 \mathrm{~mm})$ side of the rebar (except for the CFRM), and the difference is more obvious on the inner side. In addition, from Figure 13, the increase of conduction time has a positive effect on the $\mathrm{Cl}^{-}$content of the specimens with or without salt addition. In Figure 13c, for example, the differences between the $\mathrm{Cl}^{-}$content on the inner side of the rebar, with or without salt addition, are already small compared to specimens with shorter conduction times (Figure 13a,b).

For the specimens conducted with current densities of $60 \mathrm{~mA} / \mathrm{m}^{2}$ (Figure $13 \mathrm{~d}-\mathrm{f}$ ), the effect of salt addition on the $\mathrm{Cl}^{-}$content in the left and right sides of rebars is similar to that of the $20 \mathrm{~mA} / \mathrm{m}^{2}$ specimens; i.e., the $\mathrm{Cl}^{-}$content either side of the rebar is higher in the specimens with salt addition than in those without salt addition, and the difference is more obvious on the inner side of the rebars. We also found the effect that the salt addition has on the $\mathrm{Cl}^{-}$content on the outer side of the rebar; that is, additional salt leads to an increased $\mathrm{Cl}^{-}$content, which is less notable in specimens conducted with current density $60 \mathrm{~mA} / \mathrm{m}^{2}$ compared to those conducted with current density of $20 \mathrm{~mA} / \mathrm{m}^{2}$. This shows that a larger current density imposes a better migration effect on the $\mathrm{Cl}^{-}$near the rebar. Furthermore, it can be seen from Figure 13 that the $\mathrm{Cl}^{-}$content in the FRCM layer is higher when salt is added than without salt addition. In addition, the $\mathrm{Cl}^{-}$content in the FRCM is much higher than in the concrete on the outer side of the rebar. This shows that the effect of impressed current on the migration of $\mathrm{Cl}^{-}$near the rebars is more obvious, and the protective effect of the impressed current is clearer for specimens with salt addition.

Overall, for the specimens with salt addition (i.e., the simulated pre-corrosion specimens), the $\mathrm{Cl}^{-}$content on either side of the rebar increased compared to the specimens without salt addition. However, the effect of impressed current can help reduce this rise of $\mathrm{Cl}^{-}$content near the rebar, and increasing the density of impressed current as well as increasing the conduction time further reduced the rise of $\mathrm{Cl}^{-}$content on both sides of the rebars.

By analyzing Figures 10-13, it could be found that the $\mathrm{Cl}^{-}$content near the inner side of rebars was always larger than the outer side, and it is more obvious for specimens with a relatively higher current density. The reasons were mainly due to the absorption effect of the electric field and the barrier effect of rebars that influence the migration process of $\mathrm{Cl}^{-}$. In summary, the impressed current have reduced most of the $\mathrm{Cl}^{-}$near the inner side of rebars even if part of the $\mathrm{Cl}^{-}$gathered in this region; hence, the ICCP technique can play a positive and protective role for the rebars. The optimal ways to maximize the advantages of ICCP are avoiding using larger current densities and extending the conduction time.

\section{Conclusions}

In this paper, the axial compression properties of corroded RC hollow columns strengthened by FRCM and the influence of an ICCP-SS system on the migration and distribution laws of $\mathrm{Cl}^{-}$in $\mathrm{RC}$ hollow columns were studied through experiments. The following conclusions can be drawn:

(1) FRCM strengthening could increase the ultimate load of the corroded specimens considerably, and the axial displacement corresponding to the ultimate load of the strengthened specimens was larger than that of the unstrengthened specimens. This was especially notable in specimens with higher corrosion ratios;

(2) The ultimate strain of both the strengthened and unstrengthened specimens increased with the increase of corrosion ratio;

(3) During the migration process of $\mathrm{Cl}^{-}$from cathode to anode, the rebar would have a blocking effect, thus causing the $\mathrm{Cl}^{-}$content on the inner side of the rebar to always be larger than the on the outer side;

(4) For the specimens with salt addition, the $\mathrm{Cl}^{-}$content in both sides of rebars would increase compared to the specimens without salt addition. However, this increase was affected by the impressed current. A higher current density or longer conduction time reduces the increase of $\mathrm{Cl}^{-}$seen after the addition of salt; 
(5) The content of $\mathrm{Cl}^{-}$in the FRCM increased whether the specimens had salt addition or not when the impressed current was applied, which indicates that the $\mathrm{Cl}^{-}$content near the rebars had moved to the anode (i.e., the CFRP) due to the influence of the impressed current.

Author Contributions: Conceptualization, J.C. and J.-H.Z.; methodology, C.J., J.W. and J.-H.Z.; software, C.J., J.W. and J.-H.Z.; validation, J.C. and J.-H.Z.; formal analysis, C.J., J.W. and Y.F.; investigation, J.W. and Y.F.; resources, J.C. and J.-H.Z.; data curation, C.J., J.W. and Y.F.; writing-original draft preparation, J.C. and J.W. ; writing-review and editing, C.J., J.W. and J.-H.Z.; visualization, C.J., J.-H.Z. and C.-B.L.; supervision, C.J., J.-H.Z. and C.-B.L.; project administration, J.C. and J.-H.Z. All authors have read and agreed to the published version of the manuscript.

Funding: The research described in this paper was supported by the Key-Area Research and Development Program of Guangdong Province (2019B111107002), the National Key Research and Development Program of China (2018YFE0124900), the National Natural Science Foundation of China (51538007/51778370/51908016/51861165204), the Natural Science Foundation of Guangdong (2017B030311004), and the Shenzhen Science and Technology Project (GJHZ20180928155819738).

Data Availability Statement: The data presented in this study are available on request from the corresponding author.

Acknowledgments: The authors would like to thank the technicians in Zhejiang University and Shenzhen University for fabricating and testing work on the topics related to this work.

Conflicts of Interest: We declare that we have no financial and personal relationships with other people or organizations that can inappropriately influence our work, there is no professional or other personal interest of any nature or kind in any product, service and/or company that could be construed as influencing the position presented in, or the review of, the manuscript entitled "Study on the Corroded Hollow Section RC Columns Strengthened by ICCP-SS System".

\section{References}

1. Kusumawardaningsih, Y.; Hadi, M.N.S. Comparative behaviour of hollow columns confined with FRP composites. Compos. Struct. 2010, 93, 198-205. [CrossRef]

2. Shin, M.; Choi, Y.Y.; Sun, C.H.; Kim, I.H. Shear strength model for reinforced concrete rectangular hollow columns. Eng. Struct. 2013, 56, 958-969. [CrossRef]

3. $\mathrm{Xu}, \mathrm{J}$; Li, F.; Zhao, J.; Huang, L. Model of time-dependent and stress-dependent chloride penetration of concrete under sustained axial pressure in the marine environment. Constr. Build. Mater. 2018, 170, 207-216. [CrossRef]

4. Su, M.-N.; Wei, L.-L.; Zeng, Z.-W.; Ueda, T.; Xing, F.; Zhu, J.-H. A solution for sea-sand reinforced concrete beams. Constr. Build. Mater. 2019, 204, 586-596. [CrossRef]

5. Zhu, J.-H.; Su, M.-N.; Huang, J.-Y.; Ueda, T.; Xing, F. The ICCP-SS technique for retrofitting reinforced concrete compressive members subjected to corrosion. Constr. Build. Mater. 2018, 167, 669-679. [CrossRef]

6. Azam, R.; Soudki, K.; West, J.S.; Noël, M. Strengthening of shear-critical RC beams: Alternatives to externally bonded CFRP sheets. Constr. Build. Mater. 2017, 151, 494-503. [CrossRef]

7. Colajanni, P.; Fossetti, M.; Macaluso, G. Effects of confinement level, cross-section shape and corner radius on the cyclic behavior of CFRCM confined concrete columns. Constr. Build. Mater. 2014, 55, 379-389. [CrossRef]

8. Zhu, J.-H.; Wei, L.; Moahmoud, H.; Redaelli, E.; Xing, F.; Bertolini, L. Investigation on CFRP as dual-functional material in chloride-contaminated solutions. Constr. Build. Mater. 2017, 151, 127-137. [CrossRef]

9. Wei, L.-L.; Zhu, J.-H.; Ueda, T.; Su, M.-N.; Liu, J.; Liu, W.; Tang, L.P.; Xing, F. Tensile behaviour of carbon fabric reinforced cementitious matrix composites as both strengthening and anode materials. Compos. Struct. 2020, 234, 111675. [CrossRef]

10. Walraven, J. Synthesized intervention method to prolong service life of reinforced concrete structures: ICCP-SS. Struct. Concr. 2021, 22, 590-592. [CrossRef]

11. Peled, A. Confinement of Damaged and Nondamaged Structural Concrete with FRP and TRC Sleeves. J. Compos. Constr. 2007, 11, 514-522. [CrossRef]

12. Bournas, D.A.; Lontou, P.V.; Papanicolaou, C.G.; Triantafillou, T.C. Textile-reinforced mortar versus fiber-reinforced polymer confinement in reinforced concrete columns. ACI Struct. J. 2007, 104, 740.

13. Gopinath, S.; Iyer, N.R.; Gettu, R.; Palani, G.S.; Murthy, A.R. Confinement effect of glass fabrics bonded with cementitious and organic binders. Procedia. Eng. 2011, 14, 535-542. [CrossRef]

14. Di Ludovico, M.; Prota, A.; Manfredi, G. Structural upgrade using basalt fibers for concrete confinement. J. Compos. Constr. 2010, 14, 541-552. [CrossRef]

15. Ombres, L. Concrete confinement with a cement based high strength composite material. Compos. Struct. 2014, 109, $294-304$. [CrossRef] 
16. Colajanni, P.; De Domenico, F.; Recupero, A.; Spinella, N. Concrete columns confined with fibre reinforced cementitious mortars: Experimentation and modelling. Constr. Build. Mater. 2014, 52, 375-384. [CrossRef]

17. Hu, J.-Y.; Li, S.; Lu, Y.-Y.; Zhang, H.-Y.; Zhang, M.-Z. Efficiency of electrochemical extraction of chlorides in fly ash concrete using carbon fibre mesh anode. Constr. Build. Mater. 2020, 249, 118717. [CrossRef]

18. El Maaddawy, T.A.; Soudki, K.A. Effectiveness of impressed current technique to simulate corrosion of steel reinforcement in concrete. J. Mater. Civ. Eng. 2003, 15, 41-47. [CrossRef]

19. Standard Test Method for Compressive Strength of Cylindrical Concrete Specimens; ASTM C39; ASTM: West Conshohocken, PA, USA, 2012.

20. Standard Test Methods for Properties of Continuous Filament Carbon and Graphite Fiber Tows; ASTM D4018; ASTM: West Conshohocken, PA, USA, 2017.

21. Acceptance Criteria for Masonry and Concrete Strengthening Using Fabric-Reinforced Cementitious Matrix (Frcm) and Steel Reinforced Grout (Srg) Composite Systems; AC434; ICC-Evaluation Service: Whittier, CA, USA, 2016.

22. Campione, G.; Cannella, F.; Minafo, G. A simple model for the calculation of the axial load-carrying capacity of corroded RC columns. Mater. Struct. 2016, 49, 1935-1945. [CrossRef]

23. Sun, X.-Y.; Kong, H.-T.; Wang, H.-L.; Zhang, Z.-C. Evaluation of corrosion characteristics and corrosion effects on the mechanical properties of reinforcing steel bars based on three-dimensional scanning. Corros. Sci. 2018, 142, 284-294. [CrossRef] 